Article

\title{
How to Improve the Functional Capacity of Frail and Pre-Frail Elderly People? Health, Nutritional Status and Exercise Intervention. The EXERNET-Elder 3.0 Project
}

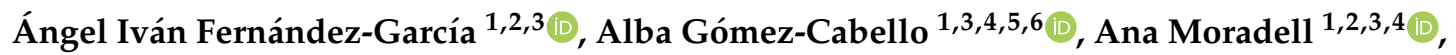 \\ David Navarrete-Villanueva ${ }^{1,3,4,7}$, Jorge Pérez-Gómez ${ }^{8} \mathbb{D}$, Ignacio Ara ${ }^{9,10}$ (D), \\ Raquel Pedrero-Chamizo ${ }^{11}$, Jorge Subías-Perié ${ }^{1,3,7}$, Borja Muniz-Pardos ${ }^{1}$ (D), \\ José A. Casajús ${ }^{1,3,4,6,7}$ and Germán Vicente-Rodríguez ${ }^{1,2,3,4,6, * \mathbb{D}}$ \\ 1 GENUD (Growth, Exercise, Nutrition and Development) Research Group, University of Zaragoza, \\ 50009 Zaragoza, Spain; angelivanfg@unizar.es (Á.I.F.-G.); agomez@unizar.es (A.G.-C.); \\ amoradell@unizar.es (A.M.); dnavarrete@unizar.es (D.N.-V.); jsubias@unizar.es (J.S.-P.); \\ borjamunizp@gmail.com (B.M.-P.); joseant@unizar.es (J.A.C.) \\ 2 Faculty of Health and Sport Science, Department of Physiatry and Nursing, University of Zaragoza, \\ 50009 Zaragoza, Spain \\ 3 Red española de Investigación en Ejercicio Físico y Salud en Poblaciones Especiales (EXERNET), \\ 50009 Zaragoza, Spain \\ 4 Instituto Agroalimentario de Aragón-IA2-(CITA-Universidad de Zaragoza), 50059 Zaragoza, Spain \\ 5 Centro Universitario de la Defensa, Zaragoza, 50090 Zaragoza, Spain \\ 6 Centro de Investigación Biomédica en Red de Fisiopatología de la Obesidad y Nutrición (CIBERObn), \\ 28029 Madrid, Spain \\ 7 Faculty of Health, Department of Physiatry and Nursing, University of Zaragoza, 50009 Zaragoza, Spain \\ 8 HEME (Health, Economy, Motricity and Education) Research Group, Faculty of Sport Sciences, \\ University of Extremadura, 10003 Caceres, Spain; jorgepg100@gmail.com \\ 9 GENUD Toledo Research Group, Universidad de Castilla-La Mancha, 45071 Toledo, Spain; \\ ignacio.ara@uclm.es \\ 10 Biomedical Research Networking Center on Frailty and Healthy Aging (CIBERFES), 28029 Madrid, Spain \\ 11 ImFine Research Group, Facultad de Ciencias de la Actividad Física y del Deporte-INEF, \\ Universidad Politécnica de Madrid, 28040 Madrid, Spain; raquel.pedrero@gmail.com \\ * Correspondence: gervicen@unizar.es; Tel.: +34-876-55-37-56
}

Received: 30 June 2020; Accepted: 29 July 2020; Published: 3 August 2020

check for updates

\begin{abstract}
Aging is associated with the impairment of health and functional capacity, and physical exercise seems to be an effective tool in frailty prevention and treatment. The purpose of this study was to present the methodology used in the EXERNET-Elder 3.0 project that aims to evaluate the immediate and residual effects and of a multicomponent exercise training program called Eelder-fit on frailty, fitness, body composition and quality of life, and also to analyse a possible dietary intake interaction according to health and metabolic status. A total of 110 frail and pre-frail elders participated in this study and were divided into a control group $(C G=52)$ and an intervention group $(\mathrm{IG}=58)$. The IG performed a supervised multicomponent exercise training program of 6 months and 3 days per week, which included strength, endurance, balance, coordination and flexibility exercises, while the CG continued with their usual daily activities. Both groups received four speeches about healthy habits along the project. Four evaluations were performed: at baseline, after 3 months of training, at the end of the training program (6 months) and 4 months after the program had ended to examine the effects of detraining. Evaluating the efficacy, safety and feasibility of this program will help to develop efficacious physical interventions against frailty. Further, protocols should be described accurately to allow exercise programs to be successfully replicated.
\end{abstract}


Keywords: aging; health; functional capacity; frailty; body composition; exercise; nutrition status; quality of life

\section{Introduction}

The aging process is accompanied by multiple changes, among which are a decline of fitness performance, which contributes to an impaired capacity to perform daily living activities (DLA) [1-4]. Seniors also suffer from other adaptations related to body composition, such as an increased fat mass, a decreased muscle mass and variations in body weight, which may be partially caused by malnutrition, a pathology highly associated with the elderly [5]. These changes can result in an increased risk of suffering from other health-related issues, such as obesity, sarcopenia, sarcopenic obesity [3], metabolic syndrome [6] and cardiovascular diseases [7-10], among others.

Considering the above, aging is likely to trigger a stage of vulnerability called frailty, which can be defined as an age-associated biological syndrome that precedes disability [11]. Frailty negatively affects multiple functioning domains, including gait and mobility, balance, muscle strength, aerobic endurance and motor processing [2,12]. This syndrome may also lead to cognitive impairment [13], urinary incontinence [14,15], sleep disorders [16] and vitamin D (vitD) deficiency [17]. These undesirable consequences of frailty are often accompanied by an increased risk of suffering undesirable health outcomes, such as falls, dependence, hospitalization or death $[2,4,18,19]$. Unfortunately, frailty is highly prevalent in older adults (>65 years old), with a frailty incidence of 7-16.3\% [20] and reaching as much as $44 \%$ when pre-frails are included [1]. Nevertheless, it is worth noting that frailty can be reversed through specific interventions, especially at early stages [20,21]. Considering the need to implement this kind of intervention prematurely, together with the aging of the world population [22,23], make the prevention, detection and treatment of frailty a major public health challenge [19,23-26] not only to improve the quality of life of older adults but also to reduce care-related costs [27].

An active lifestyle plays an important role in the prevention or attenuation of frailty. Physical activity (PA) and regular exercise have been identified as non-pharmacological strategies to enhance health-related factors [28-30], being addressed by some as "the real poly-pill" [31]. Notably, their effectiveness has been proven in all populations, with a further impact upon frailty prevention and treatment in older individuals [32]. The implementation of physical exercise is especially relevant and challenging in older individuals, who are characterized by their very sedentary lifestyle [33,34], with only a small part of them following the PA recommendations of the World Health Organization [23]. In relation to this, it should be highlighted that not all types of exercise interventions have the same effects on health-related outcomes in this population. Based on current literature, multicomponent training (MCT) programs seem to be one of the best strategies used with elderly individuals due to their positive effects upon the rate of falls, gait ability, balance, cardiorespiratory capacity, muscle strength, cognition, emotional and social aspects [35-37]. However, there is still some controversy about which MCT protocol would be the most effective, including which exercise doses would be optimal to favor the greatest adaptations possible [2,36,38]. The determination of the optimal exercise dose remains under debate, partially because studies often do not describe their exercise interventions with enough accuracy [39].

On the other hand, the effects of MCT on the body composition of frail elderly individuals have been investigated to a lesser extent and results are still controversial [40], probably due to the lack of control in confounding variables such as nutrition, which would undoubtedly bias the results. In this regard, malnutrition is a relevant pathologic condition that must be carefully supervised in the elderly [5] since it is closely associated with frailty [41]. Its development is in most cases multifactorial [42], triggering a decrease of physical and mental capacities [43] and therefore contributing to a loss of autonomy, lower quality of life and, ultimately, death [5]. Although many studies have shown the significant influence of diet on health-related issues $[44,45]$ and a positive association between exercise and nutritional 
supplementation for physical performance in frail elders [46], little is known about the influence of nutritional status as a confounding variable of exercise effects.

Recent research revealed some biochemical markers and the status of certain vitamins and hormones to be associated with frailty [47]. Specifically, important variations in vitD, the main hormone reflecting bone metabolism, could have an important effect on muscle tissue, muscle strength, risk of falling and ultimately frailty [48,49]. Accordingly, there is evidence supporting the association between hypovitaminosis D and impaired muscle function and increased disability in the elderly [50]. The association between vitD and fitness level has previously been described, although data on the elderly population are scarce [51]. Nowadays, we do not know how vitD could mediate the relationship between fitness, body composition and frailty in this vulnerable population.

The present project would also strengthen the current state of knowledge regarding the further focus on the residual effects after an exercise intervention in elderly individuals. Currently, the effects caused by exercise interruptions or detraining periods have not been widely studied. To our knowledge, there are only few studies in older people related to this topic [52-55] and all of them focused on fitness and/or functional capacity. For this reason, elucidating the consequences of exercise interruptions in other health variables is of great relevance to provide the appropriate recommendations to frail elders.

Therefore, this study aims to thoroughly present the methodology of the project entitled "Evolution of physical fitness, body composition and frailty in elderly people. Mediation of vitD and effects of an exercise program: The EXERNET Longitudinal Study (EXERNET-Elder 3.0)", providing a comprehensive insight in this research field. Furthermore, a detailed description of the MCT program called Eelder-fit will be presented, which will allow replicating the exercise intervention with frail elderly individuals in the future.

\section{Materials and Methods}

\subsection{Conceptual Framework}

The EXERNET-Elder 3.0 project is in line with the EU strategy "Health 2020", focused on promoting active aging throughout life. The project aims to revert or slow down the negative changes associated with frailty through exercise. In this way, lifestyle and, more specifically, physical activity, sedentary behaviors and exercise could all be associated with fat, lean and bone masses, physical fitness and quality of life in the frail and pre-frail elderly population. For these reasons, it is intended to evaluate the effects of a 6-month MCT program based on scientific evidence on frailty, physical fitness and body composition in addition to other variables related to lifestyle, social relationships or health-related quality of life. Furthermore, very little is known about the effects caused by interruption of exercise, so the consequences of a 4-month detraining period will be analysed in the previously mentioned variables. Moreover, some limitations have been found in the literature as there is a lack of consideration of confounder and mediator variables in exercise effects, so the possible interaction between training and diet/nutritional intake will be assessed. Also, the association between the degree of frailty and lifestyle will be evaluated, as well as the possible mediating factor of vitD. The conceptual framework of the project with the main components is shown in Figure 1.

\subsection{Study Design}

The EXERNET-Elder 3.0 project was developed between June 2018 and November 2019 and was a 10-month, non-randomized and controlled exercise intervention trial. The sample was divided into the control group (CG) and intervention group (IG) according to the volunteers' preferences/availability in order to maximize training attendance. Those elders who were unable or unwilling to attend the training sessions regularly for 6 months were directly included in the CG. The IG performed a supervised 6-month MCT followed by a 4-month detraining period in which training was interrupted and they continued with their usual lifestyle. During the present study, elders were assessed at four different time points: baseline assessments performed before the training period $\left(t_{1}\right.$ : pre-training); 
during the intervention period, when a further evaluation was performed after 3 months of training ( $t_{2}$ : in-training); and at the end of the 6 months of training to examine the immediate effects after MCT ( $t_{3}$ : post-training). Finally, the last assessment was performed to determine the effects produced by the 4-month detraining period after MCT ( $\mathrm{t}_{4}$ : post-detraining). The CG followed their usual lifestyle and routine activities throughout the entire project but underwent identical testing to the IG at baseline and follow-ups. The flow chart diagram of the study protocol is shown in Figure 2 and is based on CONSORT Statement [56].

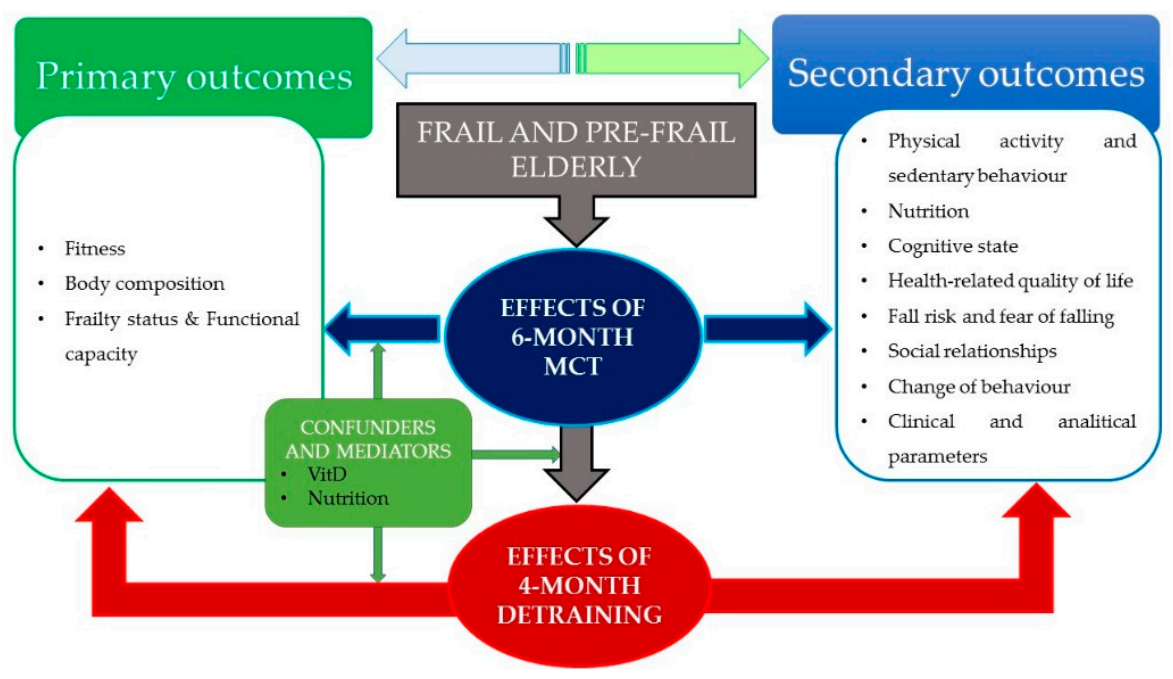

Figure 1. Conceptual framework of the EXERNET-Elder 3.0 project.

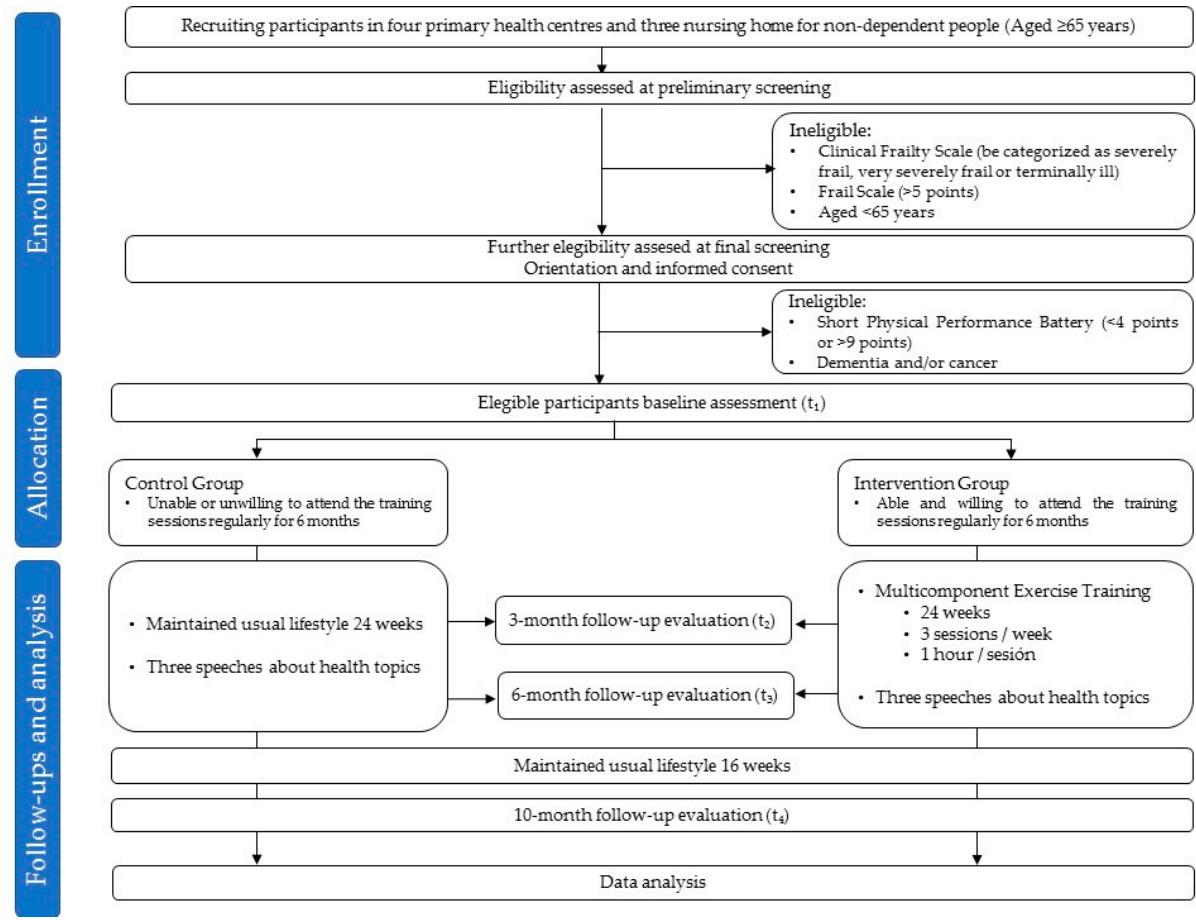

Figure 2. Flow chart diagram of the study protocol.

\subsection{Ethical Committee}

The protocol of the study has been approved by the Ethics Committee of Clinical Research of the Alcorcón Foundation University Hospital (16/50), and it followed the ethical guidelines of the 
Declaration of Helsinki 1961, revised in Fortaleza (2013) [57], complying with the Spanish legislation and legal regulations for clinical research in humans (Law 14/2007 on biomedical research). The study was registered on clinicaltrials.gov (NCT03831841). Participants received detailed information both orally and in writing about the purpose, procedures, benefits, risks and discomfort that might result from their participation in this study. All subjects that voluntarily agreed to participate signed an informed consent document prior to the first evaluation.

\subsection{Study Sample}

\subsubsection{Sample Size}

To calculate the sample size, the statistical software $G^{*}$ Power (version 3.1.9.2, Heinrich-Heine -Universität Düsseldorf) was used. Based on the study design, consisting of the measurement of two independent groups over four different periods, and assuming values of 0.05 for type I error and 0.20 for type II error (power of $80 \%$ ), a total of 28 subjects per group were required to detect variations with an average effect size $(f=0.25)$. Assuming a dropout rate of $20 \%$ in adults [58], it was necessary to recruit a total of 70 participants for this intervention. Therefore, the sample should contain at least 140 participants.

\subsubsection{Recruitment and Screening}

Recruitment and screening were performed between June and December 2018. Four primary care health centers and three nursing homes for non-dependent people of the city of Zaragoza (Spain) collaborated in the recruitment after a previous meeting with the principal investigator in which all the project information was provided. Medical doctors, nurses and heads of residences encouraged potential candidates to participate and performed a preliminary screening of volunteers based on the clinical frailty scale [38] and frail scale [59]. After that, researchers contacted eligible participants to undergo the final screening and the initial interview to collect personal data, in which volunteers received detailed information of the study and signed the informed consent document. The screening was based on the cut offs of the short physical performance battery (SPPB) for frail ( $4 \geq$ SPPB points $\leq 6)$ and pre-frail $(7 \geq$ SPPB score points $\leq 9)$ individuals [60,61]. The exclusion criteria were: to be younger than 65 years, to have been diagnosed with dementia and/or cancer and to be dependent or robust (SPPB score less than 6 or greater than 9).

\subsection{Exercise Intervention}

The intervention phase was carried out between January and June 2019 and consisted of a 24-week MCT (Eelder-fit Multicomponent Training Program).

Four specialized instructors were responsible for supervising all training sessions with a maximum of 16 participants and an instructor-to-participant ratio of 1:12. All of them always trained the same groups of participants and, to reduce interprofessional variability during the intervention, the instructors were trained to standardize the training protocol. Additionally, one of them, who was trained in sport sciences, acted as coordinator of the instructors.

The technical content of the program was based on a specific literature review $[28,32,35,36,62,63]$. Weekly planning consisted of three training sessions of $1 \mathrm{~h}$ each, composed of two strength sessions (SS) on Mondays and Fridays and one endurance session (ES) on Wednesdays. Sessions were separated by $48 \mathrm{~h}$ in order to avoid excessive muscle fatigue and were divided into $10 \mathrm{~min}$ of warm-up (with joint mobility, balance and cardiorespiratory exercises), 35-40 min of main exercise and a 10-15 min cool down consisting of flexibility exercises and cognitive tasks, which included memory, calculation, orientation, language, reasoning and executive functions exercises. During SS, elders performed different exercises to improve the strength and power levels of their upper and lower limbs and trunk, in addition to static balance and functional performance of DLA. The ES were employed to perform exercises to increase cardiorespiratory fitness levels, dynamic balance, coordination and motor skills. All exercises were adapted to the individual's functional capacity. 
There were no adverse effects or health problems due to the MCT in the IG group over the 6-month intervention period.

\subsubsection{Eelder-fit Strength Training Protocol}

In SS, elders performed a variety of exercises involving large muscle groups through single or combined multi-joint movements (e.g., chest press and fly, shoulder press, flexion and abduction, tricep pushdown, kickbacks and overhead extensions, bicep curl, pull-down, high and low back row, pull apart, lower back extension, trunk rotation, abdominal crunch through a sitting position, different types of squats, quadricep extension, leg curl, hip abduction, adduction, flexion and extension and calf raise). Furthermore, SS included static balance exercises, which consisted of maintaining different positions and, in the most advanced phases, exercises that simulate DLA. The strength training protocol was based on the three principles of the recent consensus statement by Fragala et al.: (1) individualization, including exercises adapted to different levels depending on the subject's functional capacity, (2) periodization, establishing specific goals with a systematic variation in the training stimulus to keep training sessions challenging and effective while avoiding boredom and (3) progression, increasing training demands through modifying variables such as intensity, execution velocity, coordination level (lower and upper limbs separately or simultaneously), recovery times (from 60 to $90 \mathrm{~s}$ ) or volume, which involved six to eight types of exercises, one to three sets and between eight and 15 repetitions. For the present strength training regime, three different execution velocities were determined and programed for every exercise: low and moderate velocities were those for which concentric and eccentric phases were performed in approximately 4 and $2 \mathrm{~s}$, respectively. Additionally, high-velocity repetitions were those executed as fast as possible during the concentric phase, followed by a controlled eccentric phase (approximately $2 \mathrm{~s}$ ). Regarding the principle of progression, no more than one variable (e.g., intensity or volume) was increased at a time with respect to its previous session. Notably, the increase of intensity was sometimes accompanied by a decrease in volume (i.e., number of repetitions) to ensure a progressive and safe adaptation. Although the load increase was programed beforehand through the periodization program, trainers were in charge of adapting the amount of increase according to individual toleration and feelings. Static balance exercises progressed through increasing the number of sets (from two to three) and exercise time (from 15 to $60 \mathrm{~s}$ ), in addition to decreasing limb involvement (with two arms at the beginning, one hand later and finally none if possible) or base support (both feet together side by side, semi-tandem, tandem and only with one foot) and input of information from the senses (e.g., one eye closed). Balance exercises were included both in the warm-up and the main part of the session. The equipment used for SS were elastic resistance bands, free weights (dumbbells, weighted anklets and medicine balls) and fit balls. Strength planning was divided into four phases showed in Table 1, with specific objectives and a standardized framework.

\section{Familiarization Period (Weeks 1-4)}

The aim of this phase was to generate a progressive adaptation to exercise and to focus on the exercise technique. During the first 4 weeks, SS had six to seven lower and upper body exercises, with one to two sets of eight to ten repetitions with a $90 \mathrm{~s}$ rest between sets. Elders used light weights they could easily lift for every exercise and they were instructed to correctly perform exercises at low execution velocity with constant supervision and feedback from the instructors. Furthermore, two balance exercises of 15-20 s were included and performed two times for each one.

\section{Accumulation Period (Weeks 5-14)}

During the next 10 weeks, the main purpose was to develop strength levels through seven to eight exercises of the trunk and lower and upper limbs, with two sets of 10-15 moderate velocity repetitions with a timed rest in between of $60 \mathrm{~s}$. In the same way as in the previous phase, instructors provided elders with constant feedback on every repetition to maintain the correct execution velocity. Balance training was composed of two exercises of $30 \mathrm{~s}$ performed twice for each one. 
Table 1. Eelder-fit strength periodization.

\begin{tabular}{|c|c|c|c|c|c|c|c|c|c|c|c|c|c|c|c|c|c|c|c|c|c|c|c|c|}
\hline Phase & \multirow{2}{*}{\multicolumn{4}{|c|}{$\begin{array}{l}\text { Familiarization (Weeks 1-4) } \\
\text { Cause Training Adaptations }\end{array}$}} & \multicolumn{10}{|c|}{ Accumulation (Weeks 5-14) } & \multicolumn{7}{|c|}{ Transformation (Weeks 15-21) } & \multirow{2}{*}{\multicolumn{3}{|c|}{$\begin{array}{c}\text { Functional (Weeks 22-24) } \\
\text { Improve Performance DLA }\end{array}$}} \\
\hline \multirow[t]{2}{*}{ Strength Goals } & & & & & \multicolumn{10}{|c|}{ Increase Strength Levels } & \multirow{2}{*}{\multicolumn{4}{|c|}{$\begin{array}{c}\begin{array}{c}\text { Enhance Intermuscular } \\
\text { Coordination }\end{array} \\
\begin{array}{c}\text { Increase Muscle Endurance } \\
\text { and Strength Level }\end{array}\end{array}$}} & \multicolumn{3}{|c|}{ Increase Power } & & & \\
\hline & \multicolumn{4}{|c|}{ Learn Technical Executions } & & & & Incr & ase $\mathrm{Mu}$ & le End & rance & & & & & & & & Inc & $\begin{array}{l}\text { ease Str } \\
\text { Levels }\end{array}$ & ngth & \multicolumn{3}{|c|}{$\begin{array}{l}\text { Increase Power } \\
\text { and Coordination }\end{array}$} \\
\hline SEx & \multicolumn{4}{|c|}{ 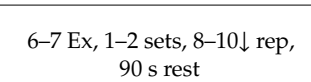 } & \multicolumn{10}{|c|}{$7-8$ Ex, 2 sets, $10-15 \rightarrow$ rep, $60 \mathrm{~s}$ rest } & \multicolumn{4}{|c|}{$\begin{array}{l}7 \text { Ex }(\mathrm{LL}+\mathrm{UL}), 2 \text { sets, } \\
12-15 \rightarrow \text { rep, 60-75 s rest }\end{array}$} & \multicolumn{3}{|c|}{$\begin{array}{c}\text { 6-7 Ex, } 2 \text { sets, } \\
12-15 \uparrow \text { rep, } 90 \text { s rest }\end{array}$} & \multicolumn{3}{|c|}{$\begin{array}{c}\text { FS: } 6 \text { Ex (DLA), } 2 \text { sets, 60-90 s, } \\
\text { 60-90 s rest (a) }\end{array}$} \\
\hline B Ex & \multicolumn{4}{|c|}{2 Ex, 2 sets, $15-20 \mathrm{~s}$} & \multicolumn{10}{|c|}{$2 \mathrm{Ex}, 2$ sets, $30 \mathrm{~s}$} & \multicolumn{4}{|c|}{ Include in S Ex } & \multicolumn{3}{|c|}{ 6-7 Ex, 2 sets, $20 \mathrm{~s}$} & \multicolumn{3}{|c|}{$\begin{array}{c}\text { FS: } 6 \text { Ex, } 2-3 \text { sets, } 30-60 \mathrm{~s} \\
\text { PS: 6-7 Ex, } 2-3 \text { sets, } 30 \mathrm{~s}\end{array}$} \\
\hline Weeks & 1 & 2 & 3 & 4 & 5 & 6 & 7 & 8 & 9 & 10 & 11 & 12 & 13 & 14 & 15 & 16 & 17 & 18 & 19 & 20 & 21 & 22 & 23 & 24 \\
\hline Exercises & 6 & 6 & 7 & 7 & $7 \bullet$ & 7 & 7 & $8 \ddagger$ & $8 \bullet$ & 8 & $8 \ddagger$ & $8 \bullet$ & 8 & $8 \ddagger$ & $7 \bullet$ & 7 & $7 \bullet$ & 7 & $6 \bullet$ & $6 \ddagger$ & 7 & $6 \bullet$ & $6 \ddagger$ & 6 \\
\hline Sets & 1 & 2 & 2 & 2 & 2 & 2 & 2 & 2 & 2 & 2 & $2^{+}$ & 2 & 2 & $2^{+}$ & 2 & 2 & 2 & 2 & 2 & $2+$ & 2 & 2 & 2 FS-3 PS & 2 FS-3 PS \\
\hline $\begin{array}{c}\text { Repetitions \& } \\
\text { execution velocity }\end{array}$ & $8 \downarrow$ & $8 \downarrow$ & $10 \downarrow$ & $10 \downarrow$ & $10 \rightarrow$ & $12 \rightarrow$ & $15 \rightarrow$ & $12 \rightarrow$ & $12 \rightarrow$ & $15 \rightarrow$ & $12 \rightarrow$ & $12 \rightarrow$ & $15 \rightarrow$ & $12 \rightarrow$ & $12 \rightarrow$ & $15 \rightarrow$ & $12 \rightarrow$ & $15 \rightarrow$ & $12 \uparrow$ & $12 \uparrow$ & $15 \uparrow$ & $\begin{array}{l}\text { FS: } 60 \mathrm{~s} \\
\text { PS: } 12 \uparrow\end{array}$ & $\begin{array}{l}\text { FS: } 75 \mathrm{~s} \\
\text { PS: } 12 \uparrow\end{array}$ & $\begin{array}{l}\text { FS: } 90 \mathrm{~s} \\
\text { PS: } 15 \uparrow\end{array}$ \\
\hline Rest time (s) & 90 & 90 & 90 & 90 & 60 & 60 & 60 & 60 & 60 & 60 & 60 & 60 & 60 & 60 & 75 & 75 & 75 & 75 & $\begin{array}{c}90 \\
(20 \mathrm{a})\end{array}$ & $\begin{array}{c}90 \\
(20 \mathrm{a})\end{array}$ & $\begin{array}{c}90 \\
(20 \mathrm{a})\end{array}$ & $\begin{array}{l}\text { FS: } 60 \\
\text { (30a) } \\
\text { PS: } 90 \\
\text { (30a })\end{array}$ & $\begin{array}{l}\text { FS: } 75 \\
(45 \text { a }) \\
\text { PS: } 90 \\
(30 \text { a })\end{array}$ & $\begin{array}{l}\text { FS: } 90 \\
(60 \text { a }) \\
\text { PS: } 90 \\
\left(30_{a}\right)\end{array}$ \\
\hline
\end{tabular}

Note: S: strength; B: balance; Ex: exercise; rep: repetitions; FS: functional sessions; PS: power sessions; LL: lower limb; UP: upper limb; DLA: daily living activities; a : active rest; $\downarrow$ : low execution velocity; $\rightarrow$ : moderate execution velocity; $\uparrow:$ high execution velocity; $\bullet$ : exercises change; and ł: overload. 
Transformation Period (Weeks 15-21)

In the following 7 weeks, the goal was to improve the muscular coordination and power. From weeks 15 to 18, elders performed sessions of seven exercises involving lower and upper limbs simultaneously, combining some of the exercises carried out in previous phases. All of them were performed twice with 12-15 repetitions executed at moderate velocity, with a resting time between sets of $75 \mathrm{~s}$. During these weeks, no balance exercises were carried out since the strength exercises themselves included balance work because of a reduction in the base of support in most exercises. From weeks 19 to 21, sessions were composed of six to seven exercises of lower and upper limbs (no simultaneous workout was performed) of 12-15 repetitions, performed twice at high velocity. The resting time between sets was $90 \mathrm{~s}$, which included a $20 \mathrm{~s}$ static balance exercise.

Functional Period (Weeks 22-24)

In this last period, a weekly session was dedicated to improving power and the other two to enhancing functional performance in DLA. Power sessions were composed of six to seven exercises involving lower and upper limbs separately or simultaneously, with two to three sets of 12-15 repetitions executed at high velocity. Elders had a $90 \mathrm{~s}$ rest between sets, of which $30 \mathrm{~s}$ were active rest, performing balance exercises. During functional sessions, elders performed two sets of six exercises consisting of dynamic movements that simulated the following DLA: shopping, walking avoiding obstacles, bringing and serving food and drink, going up and down stairs, walking fast to "take the public transport" and getting up from the floor. They carried out two sets of 60-90 s for each exercise with a resting time between sets of 60-90 s, which included a 30-60 s static balance exercise.

\subsubsection{Eelder-fit Endurance Training Protocol}

The ES included three types of exercise: aerobic basic exercises as walking, step and stationary cycle for legs, arms or both; dynamic balance and coordination exercises, including moving with different types of displacement, square stepping, changes of direction or overcoming obstacles perturbing the center of gravity; and motor skills tasks related to ball and balloon handling. The variables used to establish the progression were exercising time (30-90 s), number of exercises (six to eight), sets (one to two) and resting time (from 90 to $30 \mathrm{~s}$ ). Furthermore, other variables related to the intensity were modified through different phases with the same criteria as in the strength periodization. These variables were walking speed or cycling velocity. Moreover, the load was increased by hardening the resistance level in cycling exercises and including slight free weights, such as weighted anklets and dumbbells, while performing gait exercises, dynamic balance and motor skills tasks. In addition, the last two types of exercises also progressed through execution difficulty according to a gradual increase in coordinative demands (performing more complex movements, using smaller balls or balloons or handling proposed difficulty). As also programmed during SS, no more than one variable increased at a time with respect to its previous training session to guarantee a progressive adaptation. The equipment used for ES were psychomotricity material, agility ladders, static cycles, steps, dumbbells, weighted anklets, balls and balloons. Endurance training was divided into three phases of different duration but with common objectives: to increase aerobic capacity, to improve coordination and physical performance and to enhance motor skills and dynamic balance:

\section{Familiarization Period (Weeks 1-4)}

During the first 4 weeks, ES included seven exercises derived from the three types of exercises mentioned in the previous paragraph, performed in two sets of $30-45 \mathrm{~s}$ with a $60-90 \mathrm{~s}$ rest between sets, setting a work to rest ratio of 1:2. 
Development Period (Weeks 5-14)

From week 5 to 14, ES were composed of seven exercises carried out in two sets of 60-90 s with a 90-60 s rest between sets, progressing from a ratio of 1:1.5 to 1.5:1.

Maintenance Period (Weeks 15-21)

From weeks 15 to 21 , seven exercises were performed twice in $90 \mathrm{~s}$ sets with a rest time of $90 \mathrm{~s}$, of which 30-60 s were an active rest including static and dynamic balance exercises and simple coordination tasks using ball and balloon handling, progressing from a ratio of 2:1 to 2.5:1 (including active rest in work time).

The detailed periodization of the endurance sessions is shown in Table 2.

\subsection{Adherence and Motivation Strategies}

Trainers registered the attendance of IG participants at every session. Furthermore, a motivational strategy was used with the IG based on the maximum percentage of adherence to the MCT (number of sessions attended divided by the total number of programed sessions). The three participants of each IG with the highest level of attendance received sports equipment as an award.

In addition, all participants (IG and CG) received three speeches throughout the study on the following health topics: "Functional capacity and frailty", "Nutritional recommendation for older people" and "Physical exercise to improve health in older people". A final talk was given after the last evaluation ( $t_{4}$ : post-detraining) in order to inform about the individual (if requested) and overall results of the project. The main objective of the speeches was to engage CG participants during the project and reduce the possible burden caused by multiple evaluation periods.

Moreover, doctors and nurses of health centers and heads of residences involved in the project encouraged all participants to stay involved in the project, especially at the beginning.

\subsection{Evaluation and Equipment}

Tables 3-7 show a summary of primary, secondary and independent variables, together with the equipment used and the evaluation periods in which they were tested. 
Table 2. Eelder-fit endurance periodization.

\begin{tabular}{|c|c|c|c|c|c|c|c|c|c|c|c|c|c|c|c|c|c|c|c|c|c|}
\hline \multirow{3}{*}{ Aerobic and Skills Goals } & \multicolumn{21}{|c|}{ Increase Aerobic Capacity $\left(\mathrm{VO}_{2} \mathrm{Max}\right)$} \\
\hline & \multicolumn{21}{|c|}{ Improve Coordination and Functional Performance } \\
\hline & \multicolumn{21}{|c|}{ Enhance Motor Skills and Dynamic Balance } \\
\hline Phase & \multicolumn{4}{|c|}{ Familiarization Period (Weeks 1-4) } & \multicolumn{10}{|c|}{ Development Period (Weeks 5-14) } & \multicolumn{7}{|c|}{ Maintenance Period (Weeks 15-21) } \\
\hline Method summary & \multicolumn{4}{|c|}{7 Ex, 2 sets of $35-40 \mathrm{~s}, 60-90 \mathrm{~s}$ rest } & \multicolumn{10}{|c|}{7 Ex, 2 sets of $60-90 \mathrm{~s}, 90-60 \mathrm{~s}$ rest } & \multicolumn{7}{|c|}{$7 \mathrm{Ex}, 2$ sets of $90 \mathrm{~s}, 90 \mathrm{~s}$ rest $\left(30-60 \mathrm{~s}_{\mathrm{a}}\right)$} \\
\hline Weeks & 1 & 2 & 3 & 4 & 5 & 6 & 7 & 8 & 9 & 10 & 11 & 12 & 13 & 14 & 15 & 16 & 17 & 18 & 19 & 20 & 21 \\
\hline Exercises & 7 & 7 & 7 & 7 & $7 \bullet$ & 7 & 7 & $7 \ddagger$ & $7 \bullet$ & 7 & 7 & $7 \ddagger$ & $7 \bullet$ & 7 & 7 & $7 \ddagger$ & $7 \bullet$ & 7 & 7 & $7 \ddagger$ & 7 \\
\hline Sets & 2 & 2 & 2 & 2 & 2 & 2 & 2 & 2 & 2 & 2 & 2 & $2^{\top}$ & 2 & 2 & 2 & 2 & 2 & 2 & 2 & $2^{\top}$ & 2 \\
\hline Time (s) & 30 & 30 & 45 & 45 & 60 & 60 & 60 & 60 & 75 & 75 & 75 & 75 & 90 & 90 & 90 & 90 & 90 & 90 & 90 & 90 & 90 \\
\hline Rest time (s) & 60 & 60 & 90 & 90 & 90 & 90 & 75 & 75 & 75 & 75 & 60 & 60 & 60 & 60 & $90(30 \mathrm{a})$ & $90\left(30_{a}\right)$ & $90(45$ a) & $90(45$ a) & $90(60 \mathrm{a})$ & $90\left(60_{a}\right)$ & $90(60$ a $)$ \\
\hline Total session WT (min) & 7 & 7 & 10.5 & 10.5 & 14 & 14 & 14 & 14 & 17.5 & 17.5 & 17.5 & 17.5 & 21 & 21 & $21+7 a$ & $21+7 a$ & $\begin{array}{c}21+ \\
10.5\end{array}$ & $\begin{array}{c}21+ \\
10.5\end{array}$ & $21+14 a$ & $21+14 a$ & $21+14 a$ \\
\hline Ratio (WT:RT) (s) & $1: 2$ & $1: 2$ & $1: 2$ & $1: 2$ & $1: 1.5$ & $1: 1.5$ & $1: 1.25$ & $1: 1.25$ & $1: 1$ & $1: 1$ & $1.25: 1$ & $1.25: 1$ & $1.5: 1$ & $1.5: 1$ & $2: 1$ & 2:1 & $2.25: 1$ & $2.25: 1$ & $2.5: 1$ & $2.5: 1$ & $2.5: 1$ \\
\hline
\end{tabular}

Note: Method: methodology: Ex: exercise; WT: work time; RT: rest time; a: active rest; $\bullet$ : exercises change; and ¥: increase task difficulty or overload. 
Table 3. Summary of primary outcome measures.

\begin{tabular}{|c|c|c|c|c|}
\hline Outcome/Variable & Test/Method & Data Collection & Equipment & Timeline Evaluation Period \\
\hline \multicolumn{5}{|l|}{ FITNESS } \\
\hline \multicolumn{5}{|l|}{ Balance and agility } \\
\hline Static balance & Flamingo test & Time holding balance on one foot & $\begin{array}{l}\text { Digital stopwatch (Fisher Scientific, } \\
\text { Bartlesville, OK, USA) }\end{array}$ & $\mathrm{t}_{1}, \mathrm{t}_{2}, \mathrm{t}_{3}, \mathrm{t}_{4}$ \\
\hline Agility and dynamic balance & $\begin{array}{l}2.45 \text {-m up-and-go test } \\
\text { TUG } \\
\text { TUGcog }\end{array}$ & $\begin{array}{l}\text { Time spent to rise from a chair, walk } 2.45 \mathrm{~m} \text {, turn, come back and sit } \\
\text { Time spent to rise from a chair, walk } 3 \mathrm{~m} \text {, turn, come back and sit } \\
\text { The same as TUG but adding a cognitive task while performing the test }\end{array}$ & $\begin{array}{l}\text { Digital stopwatch (Fisher Scientific, } \\
\text { Bartlesville, OK, USA), chair and a cone }\end{array}$ & $\mathrm{t}_{1}, \mathrm{t}_{2}, \mathrm{t}_{3}, \mathrm{t}_{4}$ \\
\hline \multicolumn{5}{|l|}{ Flexibility } \\
\hline Lower limb flexibility & Chair sit and reach test & $\begin{array}{l}\text { Distance from the tips of the middle fingers to the toe end of the shoe }(\mathrm{cm}) \\
\text { performed from a sitting position with one leg extended }\end{array}$ & $\begin{array}{l}\text { Rosscraft Anthrotape (Rosscraft } \\
\text { Innovations Inc., Vancouver, BC, Canada) }\end{array}$ & $\mathrm{t}_{1}, \mathrm{t}_{2}, \mathrm{t}_{3}, \mathrm{t}_{4}$ \\
\hline Upper limb flexibility & Back scratch test & $\begin{array}{l}\text { Distance of overlap or the distance between the tips of the middle fingers of } \\
\text { both arms }\end{array}$ & $\begin{array}{l}\text { Rosscraft Anthrotape (Rosscraft } \\
\text { Innovations Inc., Vancouver, BC, Canada) }\end{array}$ & $\mathrm{t}_{1}, \mathrm{t}_{2}, \mathrm{t}_{3}, \mathrm{t}_{4}$ \\
\hline \multicolumn{5}{|l|}{ Dynamic strength } \\
\hline Lower limb strength & Chair stand test & Number of stands from a chair & $\begin{array}{l}\text { Digital stopwatch (Fisher Scientific, } \\
\text { Bartlesville, OK, USA) and a chair }\end{array}$ & $t_{1}, t_{2}, t_{3}, t_{4}$ \\
\hline Upper limb strength & Arm curl test & Number of curl lifts & $\begin{array}{l}\text { Digital stopwatch (Fisher Scientific, } \\
\text { Bartlesville, OK, USA), and dumbbells of } \\
2.5 \text { and } 4 \mathrm{~kg} \text {. }\end{array}$ & $\mathrm{t}_{1}, \mathrm{t}_{2}, \mathrm{t}_{3}, \mathrm{t}_{4}$ \\
\hline \multicolumn{5}{|l|}{ Maximum isometric strength } \\
\hline Grip strength & Handgrip test & $\mathrm{PF}(\mathrm{kg})$ & $\begin{array}{l}\text { Dynamometer (Takei TKK 5401, Takei } \\
\text { Scientific Instruments, Tokyo, Japan) }\end{array}$ & $t_{1}, t_{2} t_{3}, t_{4}$ \\
\hline $\begin{array}{l}\text { Shoulder abduction } \\
\text { Elbow flexion } \\
\text { Knee extension }\end{array}$ & Hand-held Dynamometer & $\operatorname{PF}(\mathrm{kg}), \mathrm{TPF}(\mathrm{s}$.$) and AVG-F (Kg)$ & $\begin{array}{l}\text { Dynamometer (Lafayette Manual Muscle } \\
\text { Testing Systems, Lafayette, IN, USA) }\end{array}$ & $t_{1}, t_{3}, t_{4}$ \\
\hline \multicolumn{5}{|l|}{ Walking speed } \\
\hline Maximum gait speed & 30-m walk test & Time spent in covered $30-\mathrm{m}$ as fast as possible & $\begin{array}{l}\text { Digital stopwatch (Fisher Scientific, } \\
\text { Bartlesville, OK, USA), and cones }\end{array}$ & $t_{1}, t_{2}, t_{3}, t_{4}$ \\
\hline Usual gait speed & 6-m usual walking test & Time spent in covered 6-m as usual gait speed & $\begin{array}{l}\text { Digital stopwatch (Fisher Scientific, } \\
\text { Bartlesville, OK, USA), and cones }\end{array}$ & $t_{1}, t_{2}, t_{3}, t_{4}$ \\
\hline \multicolumn{5}{|l|}{ Aerobic endurance } \\
\hline Cardiorespiratory fitness & 6-min walk test & Maximum distance covered in 6-min time limit & $\begin{array}{l}\text { Digital stopwatch (Fisher Scientific, } \\
\text { Bartlesville, OK, USA), and cones }\end{array}$ & $\mathrm{t}_{1}, \mathrm{t}_{2}, \mathrm{t}_{3}, \mathrm{t}_{4}$ \\
\hline
\end{tabular}

Note: TUG: timed up-and-go test; TUGcog: timed up-and-go test with cognitive task; PF: peak force; TPF: time peak force; AVG-F: average force; $\mathrm{t}_{1}$ : pre-training evaluation; $\mathrm{t}_{2}$ : in-training evaluation; $t_{3}$ : post-training evaluation; and $t_{4}$ : post-detraining evaluation. 
Table 4. Summary of primary outcome measures (continued).

\begin{tabular}{|c|c|c|c|c|}
\hline Outcome/Variable & Test/Method & Data Collection & Equipment & Timeline Evaluation Period \\
\hline \multicolumn{5}{|c|}{$\begin{array}{c}\text { FRAILTY STATUS \& } \\
\text { FUNCTIONAL CAPACITY }\end{array}$} \\
\hline & SPPB & Static balance, gait speed and lower strength & $\begin{array}{l}\text { Digital stopwatch (Fisher Scientific, Bartlesville, OK, USA), } \\
\text { cones and a chair of } 90 \mathrm{~cm}\end{array}$ & $\mathrm{t}_{1}, \mathrm{t}_{2}, \mathrm{t}_{3}, \mathrm{t}_{4}$ \\
\hline & Frailty phenotype of Fried & $\begin{array}{l}\text { Shrinking or unintentional weight loss, weakness (grip strength), } \\
\text { poor endurance and energy, slowness and low physical activity level. }\end{array}$ & $\begin{array}{c}\text { Dynamometer (Takei TKK 5401, Takei Scientific } \\
\text { Instruments, Tokyo, Japan) }\end{array}$ & $\mathrm{t}_{1}, \mathrm{t}_{2}, \mathrm{t}_{3}, \mathrm{t}_{4}$ \\
\hline & Questionnaire & Degree of disease and dependence for DLA & Adapted version of the clinical frailty scale & $t_{0}$ \\
\hline & & Fatigue, resistance, ambulation, illnesses and loss of weight & Frail scale questionnaire & $\mathrm{t}_{0}$ \\
\hline \multicolumn{5}{|c|}{ BODY COMPOSITION } \\
\hline \multicolumn{5}{|c|}{ BMD and strength indices } \\
\hline & pQCT & $\begin{array}{c}\text { Bone size, mass, apparent tissue density and geometry of trabecular } \\
\text { and cortical bone in radius and tibia of non-dominant limbs (leg at } \\
4 \%, 38 \% \text { and } 66 \% \text { sites and forearm at } 4 \% \text { and } 66 \% \text { ) }\end{array}$ & XCT 2000 pQCT Scanner, Ortometrix, INC, Naples, FL, USA & $t_{1}, t_{3}$ \\
\hline \multicolumn{5}{|c|}{$\begin{array}{l}\text { Body height, weight, fat mass } \\
\text { and muscle mass }\end{array}$} \\
\hline & Portable stadiometer & Height & Stadiometer (SECA, Hamburg, Germany) & $t_{1}$ \\
\hline & BIA & Weight, FFM, FMT and FM\% & TANITA BC 418-MA (Tanita Corp., Tokyo, Japan) & $t_{1}, t_{2}, t_{3}, t_{4}$ \\
\hline & pQCT & $\begin{array}{l}\text { Muscle area, muscle size index, muscle density, and index of } \\
\text { intramuscular fat (forearm and leg } 66 \% \text { site scans) }\end{array}$ & XCT 2000 pQCT Scanner, Ortometrix, INC, Naples, FL, USA & $t_{1}, t_{3}$ \\
\hline BMI & BMI $=$ weight $/$ height ${ }^{2} ; \mathrm{kg} / \mathrm{m}^{2}$ & Height and weight & $\begin{array}{c}\text { Stadiometer (SECA, Hamburg, Germany) and TANITA BC } \\
\text { 418-MA (Tanita Corp., Tokyo, Japan) }\end{array}$ & $t_{1}, t_{2}, t_{3}, t_{4}$ \\
\hline
\end{tabular}

Anthropometry

ISAK protocol

Circumferences of arm, waist, hip and calf were registered

Rosscraft Anthrotape (Rosscraft Innovations Inc

Note: SPPB: Short Physical Performance Battery; DLA: daily living activities; BMD: bone mineral density; pQCT: peripheral quantitative computed tomography; FMT: total fat mass;

FFM: fat free mass; FM\%: fat mass percentage; BIA: bioelectrical impedance analysis; BMI: body mass index; ISAK: International Society for the Advancement of Kinanthropometry; $t_{0}$ : screening evaluation; $t_{1}$ : pre-training evaluation; $t_{2}$ : in-training evaluation; $t_{3}$ : post-training evaluation; and $t_{4}$ : post-detraining evaluation. 
Table 5. Summary of secondary outcome measures.

\begin{tabular}{|c|c|c|c|c|}
\hline Outcome/Variable & Test/Method & Data Collection & Equipment & Timeline Evaluation Period \\
\hline \multicolumn{5}{|c|}{$\begin{array}{l}\text { PHYSICAL ACTIVITY AND } \\
\text { SEDENTARY BEHAVIOR }\end{array}$} \\
\hline & Accelerometery & Active and sedentary periods during a week & $\begin{array}{l}\text { Accelerometers GENEActiv (ActivInsights Ltd., Kimbolton, } \\
\text { Cambridgeshire, UK) }\end{array}$ & $\mathrm{t}_{1}, \mathrm{t}_{3}, \mathrm{t}_{4}$ \\
\hline & \multirow[t]{3}{*}{ Questionnaires } & Leisure, household and occupational activities & PASE & $\mathrm{t}_{1}, \mathrm{t}_{2}, \mathrm{t}_{3}, \mathrm{t}_{4}$ \\
\hline & & Time sitting, walking and doing household activities & EEPAQ & $t_{1}, t_{2}, t_{3}, t_{4}$ \\
\hline & & Recreational, household and occupational PA & CT-PAQ & $t_{1}$ \\
\hline \multicolumn{5}{|l|}{ NUTRITION } \\
\hline & \multirow[t]{2}{*}{ Questionnaires } & $\begin{array}{l}\text { Frequency of amount consumption of } 12 \text { main components of the } \\
\text { MedDiet and food habits related to it }\end{array}$ & MEDAS & $t_{1}, t_{3}, t_{4}$ \\
\hline & & $\begin{array}{l}\text { Dietary intakes of total calories, protein, fats, carbohydrate, alcohol, } \\
\text { cholesterol, fibre and vitamins A and C }\end{array}$ & FFQ & $\mathrm{t}_{1}$ \\
\hline & $\begin{array}{l}\text { Questionnaire and } \\
\text { anthropometry }\end{array}$ & $\begin{array}{l}\text { Nutrition, subjective health, BMI, calf circumference and } \\
\text { midarm circumference }\end{array}$ & $\begin{array}{l}\text { MNA and Rosscraft Anthrotape (Rosscraft Innovations Inc., } \\
\text { Vancouver, BC, Canada) }\end{array}$ & $t_{1}, t_{3}, t_{4}$ \\
\hline COGNITIVE STATE & Questionnaire & $\begin{array}{l}\text { Mental functions (vocal responses, orientation, memory, attention } \\
\text { and ability to name and follow verbal and written commands) }\end{array}$ & MMS & $\mathrm{t}_{1}, \mathrm{t}_{3}, \mathrm{t}_{4}$ \\
\hline \multicolumn{5}{|l|}{$\begin{array}{l}\text { HEALTH-RELATED } \\
\text { QUALITY OF LIFE }\end{array}$} \\
\hline QoL & Questionnaires & $\begin{array}{l}\text { Mobility, self-care, main activity, social relationships, pain, mood and } \\
\text { health subjective perception }\end{array}$ & EQ-5D & $t_{1}, t_{2}, t_{3}, t_{4}$ \\
\hline \multirow[t]{2}{*}{ DLA performance } & \multirow[t]{2}{*}{ Questionnaires } & $\begin{array}{l}\text { Telephoning, shopping, food preparation, housekeeping, laundering, } \\
\text { use of transportation, use of medicine and financial behavior }\end{array}$ & IADL & $t_{1}, t_{3}, t_{4}$ \\
\hline & & $\begin{array}{l}\text { Feeding, bathing, grooming, dressing, bowel control, bladder control, } \\
\text { toileting, chair transfer, ambulation and stair climbing }\end{array}$ & BI & $\mathrm{t}_{1}, \mathrm{t}_{3}, \mathrm{t}_{4}$ \\
\hline
\end{tabular}

Note: PASE: physical activity scale for the elderly; EEPAQ: elderly EXERNET physical activity questionnaire; PA: physical activity; CT-PAQ: Chasan-Tarber Physical Activity Questionnaire; MedDiet: Mediterranean diet; MEDAS: Mediterranean diet adherence screener; MNA: mini nutritional assessment; FFQ: foot frequency questionnaire; MMS: mini-mental state; EQ-5D: Euroqol-5D questionnaire; IADL: instrumental activities of daily living scale; BI: Barthel index; $t_{1}$ : pre-training evaluation; $t_{2}$ : in-training evaluation; $t_{3}$ : post-training evaluation; and $t_{4}$ : post-detraining evaluation. 
Table 6. Summary of secondary outcome measures (continued).

\begin{tabular}{|c|c|c|c|c|}
\hline Outcome/Variable & Test/Method & Data Collection & Equipment & Timeline Evaluation Period \\
\hline \multicolumn{5}{|l|}{$\begin{array}{l}\text { FALL RISK AND FEAR } \\
\text { OF FALLING }\end{array}$} \\
\hline & \multirow[t]{2}{*}{ Questionnaires } & Fear of falling when carrying out different ADL & FES-I & $\mathrm{t}_{1}, \mathrm{t}_{3}, \mathrm{t}_{4}$ \\
\hline & & Fear of falling, falls suffered and their consequences & EXERNET 3.0 general questionnaire & $t_{1}, t_{2}, t_{3}, t_{4}$ \\
\hline CHANGE OF BEHAVIOR & Questionnaire & $\begin{array}{l}\text { Participation in moderate PA in the present and past, } \\
\text { and intention to participate in the future }\end{array}$ & TMPECQ & $t_{1}, t_{3}, t_{4}$ \\
\hline SOCIOTYPE & Questionnaire & $\begin{array}{l}\text { Quality of the relationships with family, friends } \\
\text { and acquaintances }\end{array}$ & SOCQ & $t_{1}, t_{3}, t_{4}$ \\
\hline \multicolumn{5}{|l|}{$\begin{array}{c}\text { CLINICAL AND } \\
\text { ANALYTICAL PARAMETERS }\end{array}$} \\
\hline Blood test & $\begin{array}{l}\text { Direct venous puncture fasting } \\
\text { in the antecubital vein }(10 \mathrm{~mL})\end{array}$ & Basic blood count, serology and vitD & $\begin{array}{l}\text { Syringe, blood tubes, centrifuge, freezer, VITROS } \\
\text { 25-OH VitD Total Reagent Pack and VITROS 25-PH } \\
\text { vitD Total Calibrators }\end{array}$ & $t_{1}, t_{3}, t_{4}$ \\
\hline Blood pressure & Ankle-arm index & $\begin{array}{l}\text { AAI = maximum systolic blood pressure in the ankle } \\
\text { or foot/maximum systolic blood pressure in the arm }\end{array}$ & $\begin{array}{l}\text { Sphygmomanometer (Omron, HEM-7112), manual } \\
\text { continuous Doppler probe (Hadeco Bidop ES-100V3, } \\
\text { Düsseldorf, Germany) and conductive gel }\end{array}$ & $\mathrm{t}_{1}, \mathrm{t}_{3}, \mathrm{t}_{4}$ \\
\hline
\end{tabular}

Note: FES-I: falls efficacy scale I; TMPECQ: transtheoretical model of physical exercise changes questionnaire; SOCQ: sociotype questionnaire; vitD: vitamin D; AAI: ankle-arm index; $\mathrm{t}_{1}$ : pre-training evaluation; $t_{2}$ : in-training evaluation; $t_{3}$ : post-training evaluation; and $t_{4}$ : post-detraining evaluation.

Table 7. Summary of independent variables measures.

\begin{tabular}{clcc}
\hline Outcome/Variable & Test/Method & Data Collection & Equipment/Method \\
\hline COMPLEMENTARY INFORMATION & & & \\
\hline Personal, socioeconomic and educational & Questionnaire & Age, sex and socioeconomic and educational level & EXERNET 3.0 general questionnaire \\
\hline Health-related & Questionnaire & $\begin{array}{c}\text { Urinary incontinence, insomnia, sun exposure, } \\
\text { drug and tobacco consumption and chronic pains }\end{array}$ & EXERNET 3.0 general questionnaire \\
\hline
\end{tabular}

Note: $\mathrm{t}_{1}$ : pre-training evaluation; $\mathrm{t}_{2}$ : in-training evaluation; $\mathrm{t}_{3}$ : post-training evaluation; and $\mathrm{t}_{4}$ : post-detraining evaluation. 


\subsubsection{Fitness}

Fitness assessments were based on the Senior Fitness Test [64] and the Eurofit Battery [65], in addition to other complementary tests to evaluate the following variables.

Balance and Agility

Static balance was evaluated through the flamingo test [65], which measures the maximum time (s) the elder is able to stand on one foot with arms on hips and with the contralateral foot leaning on the opposite ankle. Agility and dynamic balance were assessed through three different tests: $2.45 \mathrm{~m}$ up-and-go test [64], timed up-and-go test (TUG) [66] and TUG with a simultaneous cognitive task (TUGcog) [67]. They measure the time (s) taken to rise from a chair, turn around a cone situated at $2.45 \mathrm{~m}$ ( $2.45 \mathrm{~m}$ up-and-go) or $3 \mathrm{~m}$ (TUG and TUGcog), come back and sit. During TUGcog, participants must name as many different animals or colors as possible out loud as they perform the test as quickly as possible. All balance and agility tests were performed twice with the best performance recorded, except TUGcog, which was done once. Agility and dynamic balance tests were performed from a chair of $43 \mathrm{~cm}$ seat height.

\section{Flexibility}

Lower limb flexibility was evaluated through the chair sit-and-reach test [64], which consisted of measuring the distance $(\mathrm{cm})$ from the tips of the middle fingers to the upper part of the shoe, testing one leg at a time. This test was performed in a sitting position (seat height of $43 \mathrm{~cm}$ ) with the tested leg fully extended. Upper limb flexibility was tested by the back scratch test [64], in which the distance $(\mathrm{cm})$ of overlap, or the distance between the tips of the middle fingers of both arms, was measured. The test was performed from a standing position, placing one arm over the same shoulder with the elbow pointed up and palm down, while the other arm was at the back of the waist with the elbow pointed down and the palm up. In both tests, there were two attempts, one with each limb (right and left) and the best performance was recorded.

\section{Dynamic Strength}

Lower limb strength was tested by the chair stand test [64], which measured the number of times elders were able to stand up from and sit down on a chair in $30 \mathrm{~s}$. Upper limb strength was tested by the arm curl test [64], in which elders were required to lift a dumbbell of $4 \mathrm{~kg}$ (men) or $2.5 \mathrm{~kg}$ (women) to the maximum number of repetitions within $30 \mathrm{~s}$. In both tests, if the last repetition was not completed but at least got to the middle of the movement, half a repetition was considered. In both tests a chair with a seat height of $43 \mathrm{~cm}$ was used and there was one attempt in the first test and two in the second one (right and left limb).

\section{Maximum Isometric Strength}

Handgrip strength was tested using a digital dynamometer (Takei TKK 5401, Tokyo, Japan) with a precision of $0.1 \mathrm{~kg}$. When performing the test, elders were standing with the dynamometer held with the arm straight down, shoulder slightly abducted and wrist in a neutral position. Participants were asked and encouraged to apply the maximum strength possible. Each participant performed the test twice with each hand (alternately) with at least a 30-s period of rest between attempts, with the best record being registered $(\mathrm{kg})$.

In addition, maximum isometric torque strength was measured in shoulder abduction (SA), elbow flexion (EF) and knee extension (KE) by a hand-held dynamometer (Lafayette Manual Muscle Testing Systems, Lafayette, IN, USA). All three tests were performed in a sitting position (seat height of $43 \mathrm{~cm}$ ) with the back stabilized on the backrest, and participants were instructed and monitored to maintain the trunk in a stable position. For SA and EF, the shoulder and elbow were in a neutral position, with the forearm neutral in SA and supinated in EF while, in KE, knees and hips were flexed $90^{\circ}$. 
The hand-held dynamometer was placed proximal to the styloid processes and malleolus in the upper and lower limb tests, respectively, and the shaft of the dynamometer was perpendicular to the segment tested. The test protocol consisted of two maximal trials with the dominant limb (alternating over the three exercises). Elders were encouraged to perform a maximal isometric contraction during $6 \mathrm{~s}$ with a 30 -s rest between actions. Peak force, time to peak force and average force were recorded $(\mathrm{kg})$ in each exercise and attempt.

Aerobic Endurance

Cardiorespiratory fitness was tested through the 6-min walk test [64], in which elders had to cover as much distance as possible in the 6-min time limit around a rectangular course of $46 \mathrm{~m}$. At least two participants had to perform the test simultaneously.

Walking Speed

Maximum walking speed was evaluated through the 30-m walk test [68], which measures the time spent to walk $30 \mathrm{~m}$ as fast as possible without running. Additionally, usual walking speed was tested through the 6-m usual walking test [69], which consisted of walking $6 \mathrm{~m}$ at usual pace. Both tests were performed twice.

\subsubsection{Frailty Status \& Functional Capacity}

According to the literature, frailty can be defined with different methods and criteria. The scales and procedures used in this project are shown below.

\section{Frail Scale}

The frail scale is a five-item questionnaire that measures fatigue (feeling tired in the last 4 weeks), resistance (being able to walk up 10 steps without resting), ambulation (having any difficulty while walking several hundred meters), illnesses (having at present or in the past at least five illness of a group of 11) and loss of body weight during the last year (more than 5\%) [59].

\section{Clinical Frail Scale (Adapted Version)}

The clinical frail scale offers a clearer "snapshot" assessment based on clinical judgment according to the degree of disease and dependence for DLA. This scale includes nine categories ranging from 1 (very fit) to 9 (terminally ill) [38]. Given the inclusion criteria of the study, an adapted version of three "snapshots", corresponding to vulnerable, mildly frail and moderately frail status, was used in the recruitment phase performed in the health centers and nursing homes.

\section{Frailty Phenotype of Fried}

This test is based on five items: unintentional weight loss (more than $4.5 \mathrm{~kg}$ in the year before or at least $5 \%$ of body weight), self-reported exhaustion (felt especially tired during the last week), weakness (low grip strength), slow usual gait speed $(4.5 \mathrm{~m})$ and low physical activity (less than $2 \mathrm{~h}$ walking per week). When three or more of these items were met, the degree of frailty was reached, while only one or two items denoted pre-frailty [19].

\section{Short Physical Performance Battery (SPPB)}

The battery measures physical performance and functional status according to level of balance (ability to stand up for $10 \mathrm{~s}$ with feet positioned in three ways: together side-by-side, semi-tandem and tandem positions), usual gait speed (time to complete a $4 \mathrm{~m}$ walk) and lower limb strength (time to rise five times from a chair). In order to assess performance, each task was scored from 0 to 4 with a total battery score of 12 points (p) [60,61] and four functional stages: dependent $(<4 p)$, frail $(4-6 p)$, pre-frail $(7-9 \mathrm{p})$ and robust $(>9 \mathrm{p})[70]$. 


\subsubsection{Body Composition and Anthropometric Measurements}

Bone Mineral Density and Strength Indices

Bone mineral density (BMD) of trabecular and cortical bone $\left(\mathrm{mg} / \mathrm{cm}^{3}\right)$, both in the radius and tibia of non-dominant limbs, were evaluated using peripheral quantitative computed tomography (pQCT) (XCT 2000 Peripheral QCT Scanner, Ortometrix, INC, Naples, FL, USA). The device provides information about cross-sectional areas related to bone size (area), mass (mineral content), apparent tissue density and geometry (spatial distribution of mass). Three image slices were acquired at $4 \%$, $38 \%$ and $66 \%$ sites for the lower leg and two at $4 \%$ and $66 \%$ for the forearm. Moreover, strength indices were calculated using a combined measurement of cross-sectional geometry and tissue density. The same technician performed all scans and image analyses.

Height, Weight, Fat Mass and Muscle Mass

Height was measured with a portable stadiometer of $2.10 \mathrm{~m}$ and a $0.001 \mathrm{~m}$ error margin (SECA, Hamburg, Germany). A portable bioelectrical impedance analyser with a $200 \mathrm{~kg}$ maximum capacity and $\mathrm{a}+/-50 \mathrm{~g}$ error margin (TANITA BC 418-MA, Tanita Corp., Tokyo, Japan) was used to assess the body weight $(\mathrm{kg})$ and to estimate the total body fat mass, the percentage of body fat and the fat-free mass. Before weighing, elders removed shoes and heavy clothes. Body mass index (BMI) was then calculated following the formula BMI $=$ weight $(\mathrm{kg}) /$ height $(\mathrm{m})^{2}$. Furthermore, cross-sectional muscle area, muscle size index, muscle density and index of intramuscular fat were evaluated through a pQCT scan of the lower leg and forearm of non-dominant limbs at the $66 \%$ sites.

\section{Anthropometrics}

The circumferences of the arm (relaxed), waist, hip and calf were registered according to the International Society for the Advancement of Kinanthropometry (ISAK) protocol [71] with Rosscraft Anthrotape (Rosscraft Innovations Inc., Vancouver, BC, Canada) by two researchers who were accredited as ISAK level 1 anthropometrists. If there were incongruences (an error greater than 1.5\%) between the first two evaluations, a third measure was performed, and the mean was recorded.

\subsubsection{Physical Activity and Sedentary Behaviors}

PA and sedentary behaviors were assessed by objective methods (accelerometry) and subjective tools (validated questionnaires).

\section{Accelerometry}

Elders wore a GENEActiv accelerometer (GA) (ActivInsights Ltd., Kimbolton, Cambridgeshire, United Kingdom) on the nondominant wrist to record PA and sedentary periods during seven consecutive days, including two weekend days. The accelerometer is waterproof, so participants did not remove it when taking a shower or when performing aquatic activities. The GA is a small, lightweight and triaxial accelerometer $(43 \times 40 \times 13 \mathrm{~mm}, 16 \mathrm{~g})$ with $500 \mathrm{MB}$ of memory that measures acceleration between -8 and +8 gravity $(\mathrm{g})$. This device has been validated to measure PA intensity or activity energy expenditure in adults [72]. The 25 GA devices used in this project were initialized to collect data at a sampling rate of $60 \mathrm{~Hz}$ [29] using the GENEA software (version 1.487, update 531).

\section{Physical Activity Scale for the Elderly (PASE)}

PASE is a 12-item questionnaire that combines information related to frequency and intensity of leisure, household and occupational activities performed in the last week [73]. 
Elderly EXERNET Physical Activity Questionnaire (EEPAQ)

EEPAQ includes three questions about the time spent sitting, walking and doing household activities per day [74].

Adapted Version of Chasan-Tarber Physical Activity Questionnaire (CT-PAQ)

A modified and shorter version of CT-PAQ [75-78] was used to assess the frequency, intensity and duration of recreational, household and occupational PA over four age periods $(15-25,26-65,>65$ years and during the last year).

\subsubsection{Nutrition}

Three different questionnaires were administered to collect information about participants' nutrition.

\section{Mediterranean Diet Adherence Screener (MEDAS)}

MEDAS is a 14-item questionnaire that reports the habitual frequency or amount of consumption of the main components and food habits of the Mediterranean diet (MedDiet). The result of this questionnaire provides information related to the adherence to the MedDiet [79-81].

\section{Mini Nutritional Assessment (MNA)}

MNA consists of 18 items of geriatric-specific assessment, composed of 15 questions related to diet, self-perception of nutritional and health state, and functionality or independence, in addition to three anthropometric parameters: BMI, calf circumference and mid-arm circumference. MNA classifies a person as well nourished, at risk or malnourished [5].

Food Frequency Questionnaire (FFQ)

A semiquantitative FFQ previously validated in Spain [44,45] was used to assess dietary intake. The questionnaire included 137 items showing their typical portion size. Daily intake was calculated by multiplying the portion size by the frequency of consumption (nine options ranging from never/almost never to six times or more per day). Nutrient intake was estimated using Spanish food composition tables and other sources of information $[82,83]$.

\subsubsection{Cognitive State}

Mini-Mental State (MMS)

MMS is an 11-item administered questionnaire that tests the cognitive aspects of mental functions in two sections with a total punctuation of 30 points. The first part evaluates vocal responses, orientation, memory and attention, and the second assesses the ability to name and follow verbal and written commands [84].

\subsubsection{Health-Related Quality of Life}

\section{Euroqol-5D Questionnaire (EQ-5D)}

EQ-5D is a questionnaire that includes five dimensions: mobility, self-care, main activity, social relationships, pain and mood. It also includes a health-reported scale ranging from 0 to 100 , with 0 being the worst imaginable state of health and 100 being the best [85]. 
Instrumental Activities of Daily Living Scale (IADL)

The IADL assesses functional competence. It is a sex-linked scale of eight points for women and five points for men. Telephoning, shopping, food preparation, housekeeping, laundering, use of transportation, use of medicine, and financial behavior were included for both genders. Food preparation, laundry and housekeeping were specific items for women [86].

Barthel Index (BI)

The $\mathrm{BI}$ is an ordinal scale of 10 items used to measure performance in DLA. It refers to mobility and self-care in DLA (feeding, bathing, grooming, dressing, bowel control, bladder control, toileting, chair transfer, ambulation and stair climbing). The index yields a total score out of 100 and allows knowing if elders are independent, need some assistance or are dependent [87-89].

\subsubsection{Fall Risk and Fear of Falling}

Falls Efficacy Scale I (FES-I)

FES-I is an interviewed questionnaire of 16 items that assesses the level of concern about fear of falling when carrying out different DLA in a four-point scale item $(1=$ not concerned at all and $4=$ very concerned) [90].

Ad-hoc Risk of Fall and Fear Questionnaire

Moreover, some more questions about the number and seriousness of falls, their consequences and fear of falling were designed ad hoc and added to the general questionnaire.

\subsubsection{Change of Behavior Aspects}

Modified Version of Transtheoretical Model of Physical Exercise Changes Questionnaire (TMPECQ)

A five-item adapted version of TMPECQ [91,92] was used to describe the different stages of elders regarding the acquisition of physical exercise habits (precontemplation, contemplation, preparation, action and maintenance).

\subsubsection{Sociotype}

Sociotype Questionnaire (SOCQ)

SOCQ is a questionnaire of 12 items (+4) used to assess the quality of relationships with family, friends, acquaintances and work/study mates (four questions for each one) [93]. This last domain was not used with elders because it was not applicable. The survey utilized a forced-choice response format using a Likert-type scale with six response options, from 0 (never) to 5 (always).

\subsubsection{Clinical and Analytical Parameters}

Blood Collection and Genomic, Proteomic and Biochemical Analysis

Venous blood sampling was performed according to the recommendations of the European Federation of Clinical Chemistry and Laboratory Medicine Working Group for Preanalytical Phase and the Latin American Working Group for Preanalytical Phase [94]. The blood collection was performed through venous puncture on the antecubital vein using a 21-gauge butterfly needle (BD Vacutainer Safety-Lok ${ }^{\mathrm{TM}}$, BD Biosciences, North Ryde, NSW 2113, Australia) with four different $4 \mathrm{~mL}$ Vacutainer ${ }^{\circledR}$ tubes (BD Biosciences, Australia), one containing citrate and three containing ethylenediaminetetraacetic acid (EDTA) and three total blood tubes. 
For the analysis of genomic and proteomic biomarkers, the blood samples were diluted 2-fold with sterile phosphate-buffered saline (PBS) 1X, and serum, plasma and lymphocytes were harvested using the Ficoll density gradient method and preserved at -80 degrees Celsius.

For the apolipoprotein E genotyping, the white blood cells were separated by centrifugation in a hypotonic EDTA solution and lysed with sodium dodecyl sulfate (SDS). The DNA was then precipitated with isopropyl alcohol and dissolved in Tris EDTA solution. Quantitative polymerase chain reaction (qPCR) reactions were made in a StepOne Plus system using TaqMan Genotyping MasterMix and a mixture of pre-made TaqMan single nucleotide polymorphism (SNP) genotyping assays (rs429358 and rs7412). SDS 2.4 software was used for genotype calling (all qPCR reagents and systems were obtained from Life Technologies).

Blood samples for biochemical analysis were allowed to clot for at least $60 \mathrm{~m}$ and centrifuged, and serum was collected. The biochemical analysis from this serum and hematologic analysis were analyzed within $24 \mathrm{~h}$ after collection.

Additionally, vitD $(25(\mathrm{OH}) \mathrm{D})$ will be analysed in plasma through the ELISA kits (VITROS 25-OH Vitamin D Total Reagent Pack and VITROS 25-OH Vitamin D Total Callibrators) using the immunodiagnostic system VITROS 3600 and VITROS 5600 Integrated System with Intellicheck ${ }^{\circledR}$ technology (UK). The VITROS 25-OH Vitamin D Total Reagent Pack kit is an enzymatic immunoassay that allows for a quantitative determination in blood serum or plasma, and it has been widely used for the study of vitD deficiency in the clinical setting. The sensitivity of this method is of $5 \mathrm{nmol} / \mathrm{L}$ $25(\mathrm{OH}) \mathrm{D}$, with a coefficient of variation under $1 \%$ and a prevalence of false positive and false negative cases lower than $5 \%$.

Blood Pressure (BP)

BP was obtained by the ankle-arm index (AAI) method, which requires a conventional sphygmomanometer (Omron, HEM-7112), a manual continuous Doppler probe (Hadeco Bidop ES-100V3, Düsseldorf, Germany) and a small amount of conductive gel. AAI of each of two extremities was obtained by the following formula: AAI = maximum systolic BP in the ankle or foot $/$ maximum systolic BP in the arm. Before measurements, elders were asked to bare four limbs and take a $5 \mathrm{~min}$ rest in a supine position. All BP measurements were done by two nurses.

\subsubsection{General Questionnaire}

Furthermore, personal and socioeconomic aspects (menstruation and menopause ages, working life, etc.) and additional information about current health situation (insomnia, urinary incontinence, sun exposure, drugs and tobacco consumption) were registered through a general questionnaire designed ad hoc for the study.

\subsection{Data Collection Procedure}

All participants were assessed by a team of nine researchers in the same places where the training sessions of the IG were developed and using the same procedures and equipment. During all assessment periods (baseline and follow-ups), the tests were carried out in the same order and each participant (IG and CG) was evaluated in two different sessions of approximately 60-90 min performed on two different days. Additionally, for the baseline assessment, there was a third session to administer the food frequency questionnaire alone due to its excessive extension (approximately $30 \mathrm{~min}$ per participant). In the first session, the tests and the order were: blood extractions (except in $\mathrm{t}_{2}$ ), body composition, anthropometric measurements and questionnaires. In the second session, blood pressure was measured in the first place, while frailty and fitness tests were performed thereafter. To avoid an excess of fatigue during the first session, participants were allowed to have breakfast before continuing with the administration of the questionnaires. 


\section{Discussion}

The current project aims to shed light on exercise recommendations for frail and pre-frail elders. To our knowledge, the effects of MCT interventions on health outcomes for this specific population have not been studied before from such a broad perspective as the present work. An additional strength of this project is that the duration of our intervention is among the most long-lasting within the literature on this topic.

The benefits of MCT in seniors have previously been reported by a recent systematic review [28], although only a few of the included studies [95-98] focused on coordination and motor skills exercises, which are accompanied by sustained concentration and a high cognitive demand [99]. This has been observed to trigger cognitive effects later in life [100]. Moreover, our exercise protocol also includes power exercises, which have proved to be feasible and beneficial in the oldest old individuals $[35,101,102]$. The development of power for the elderly is especially interesting considering that power levels decrease at a greater rate than strength levels with aging, and power has shown to be a more powerful predictor of functional disability [103].

A further limitation of the existing literature is that trial descriptions of exercise intervention are often poorly described, which greatly limits their replication or comparison. To avoid this circumstance, the present study has tried to describe with accuracy the Eelder-fit protocol, following the recommendations of Slade et al. in the Consensus on Exercise Reporting Template (CERT) [39].

Regarding the detraining effects in the elderly, there are only a few studies on this topic and conclusions remain under debate because of the large heterogeneity of these training protocols. None of the existing studies evaluated the possible variations in body composition or frailty status in response to the cessation of exercise, so our project will be pioneering and could have important practical applications and impacts on future training prescription for the elderly.

Additionally, our intervention includes some important features that have been shown to increase the effectiveness of training programs. Firstly, group-based exercise programmes, supervised by professional trainers, are more effective than home-based ones among older patients $[95,96]$. This type of program also has collateral advantages, such as the increase in long-term adherence among participants. In addition, in-person training favors social interactions, emotional well-being and general well-being [28,104]. Secondly, although there is limited scientific information in this respect, the use of positive reinforcement or modest incentives, which we implemented, have shown benefits in participation rates $[105,106]$.

Finally, a design limitation of the study should be mentioned. The randomization of participants was not performed since we had to accommodate them following their preferences/availability for pragmatic reasons.

\section{Perspective}

The EXERNET-Elder 3.0 project aims to answer a number of questions in order to better understand the effects of MCT in the domains that are affected by frailty as well as the consequences of a period of detraining. Publishing this methodological paper before the results are available has the main benefit that the paper can be critically evaluated for its methodological quality, irrespective of the results, and also that future papers from other groups could replicate and strengthen our findings. Future answers will be presented in the form of original research articles focused on the three main areas of the project: (1) frailty, (2) fitness and (3) body composition.

Author Contributions: Conceptualization, Á.I.F.-G., G.V.-R., J.A.C. and A.G.-C.; methodology, Á.I.F.-G., G.V.-R. and A.G.-C.; resources, Á.I.F.-G., G.V.-R., J.A.C., I.A. and B.M.-P.; writing-original draft preparation, Á.I.F.-G. and A.G.-C.; writing-review and editing, Á.I.F.-G., G.V.-R., J.A.C., A.G.-C., A.M., D.N.-V. and B.M.-P.; visualization, J.P.-G., J.S.-P., B.M.-P. and R.P.-C.; supervision, G.V.-R., J.A.C., A.M., D.N.-V., B.M.-P., J.P.-G., J.S.-P. and R.P.-C.; project administration, G.V.-R., J.A.C. and A.G.-C.; funding acquisition, G.V.-R., J.A.C. and I.A. All authors have read and agreed to the published version of the manuscript. 
Funding: This study was funded by "Ministerio de Economía, Industria y Competitividad” (DEP2016-78309-R), "Centro Universitario de la Defensa de Zaragoza" (UZCUD2017-BIO-01), Zaragoza City Council and the Biomedical Research Networking Center on Frailty and Healthy Aging (CIBERFES) and FEDER funds from the European Union (CB16/10/00477).

Acknowledgments: The authors are grateful to all collaborators: the nursing homes, health centers and participants whose cooperation and dedication made this study possible. Á.I.F.-G. has received a PhD grant from the Spanish government (BES-2017-081402). A.M. has received a PhD grant from “Gobierno de Aragón” (2016-2021). D.N.-V. received a grant from “Gobierno de Aragón” (DGAIIU/1/20).

Conflicts of Interest: No authors have potential conflicts of interest with reference to this paper.

\section{References}

1. Collard, R.M.; Boter, H.; Schoevers, R.A.; Oude Voshaar, R.C. Prevalence of frailty in community-dwelling older persons: A systematic review. J. Am. Geriatr. Soc. 2012, 60, 1487-1492. [CrossRef] [PubMed]

2. Giné-Garriga, M.; Roqué-Fíguls, M.; Coll-Planas, L.; Sitjà-Rabert, M.; Salvà, A. Physical exercise interventions for improving performance-based measures of physical function in community-dwelling, frail older adults: A systematic review and meta-analysis. Arch. Phys. Med. Rehabil. 2014, 95, 753-769. [CrossRef] [PubMed]

3. Gómez-Cabello, A.; Vicente Rodríguez, G.; Vila-Maldonado, S.; Casajús, J.A.; Ara, I. Aging and body composition: The sarcopenic obesity in Spain. Nutr. Hosp. 2012, 27, 22-30. [CrossRef] [PubMed]

4. Sternberg, S.A.; Schwartz, A.W.; Karunananthan, S.; Bergman, H.; Mark Clarfield, A. The identification of frailty: A systematic literature review. J. Am. Geriatr. Soc. 2011, 59, 2129-2138. [CrossRef] [PubMed]

5. Bauer, J.M.; Kaiser, M.J.; Anthony, P.; Guigoz, Y.; Sieber, C.C. The mini nutritional assessment ${ }^{\circledR}$-its history, today's practice, and future perspectives. Nutr. Clin. Pract. 2008, 23, 388-396. [CrossRef]

6. Goodpaster, B.H.; Krishnaswami, S.; Harris, T.B.; Katsiaras, A.; Kritchevsky, S.B.; Simonsick, E.M.; Nevitt, M.; Holvoet, P.; Newman, A.B. Obesity, regional body fat distribution, and the metabolic syndrome in older men and women. Arch. Intern. Med. 2005, 165, 777-783. [CrossRef] [PubMed]

7. Alonso, A.; Martínez-González, M.Á. Olive oil consumption and reduced incidence of hypertension: The SUN study. Lipids 2004, 39, 1233-1238. [CrossRef] [PubMed]

8. Bes-Rastrollo, M.; Sánchez-Villegas, A.; Gómez-Gracia, E.; Martínez, J.A.; Pajares, R.M.; Martínez-González, M.A. Predictors of weight gain in a Mediterranean cohort: The Seguimiento Universidad de Navarra Study. Am. J. Clin. Nutr. 2006, 83, 362-370. [CrossRef]

9. Martínez-González, M.A.; Sánchez-Villegas, A.; De Irala, J.; Marti, A.; Martínez, J.A. Mediterranean diet and stroke: Objectives and design of the SUN project. Nutr. Neurosci. 2002, 5, 65-73. [CrossRef]

10. Psaltopoulou, T.; Naska, A.; Orfanos, P.; Trichopoulos, D.; Mountokalakis, T.; Trichopoulou, A. Olive oil, the Mediterranean diet, and arterial blood pressure: The Greek European Prospective Investigation into Cancer and Nutrition (EPIC) study. Am. J. Clin. Nutr. 2004, 80, 1012-1018. [CrossRef]

11. Rodríguez-Mañas, L.; Féart, C.; Mann, G.; Viña, J.; Chatterji, S.; Chodzko-Zajko, W.; Gonzalez-Colaço Harmand, M.; Bergman, H.; Carcaillon, L.; Nicholson, C.; et al. Searching for an operational definition of frailty: A delphi method based consensus statement. the frailty operative definition-consensus conference project. J. Gerontol 2013, 68, 62-67. [CrossRef] [PubMed]

12. Gobbens, R.J.; Luijkx, K.G.; Wijnen-Sponselee, M.T.; Schols, J.M. Toward a conceptual definition of frail community dwelling older people. Nurs. Outlook 2010, 58, 76-86. [CrossRef] [PubMed]

13. Robertson, D.A.; Savva, G.M.; Kenny, R.A. Frailty and cognitive impairment-A review of the evidence and causal mechanisms. Ageing Res. Rev. 2013, 12, 840-851. [CrossRef] [PubMed]

14. Aniuliene, R.; Aniulis, P.; Steibliene, V. Risk factors and types of urinary incontinence among middle-aged and older male and female primary care patients in Kaunas region of Lithuania: Cross sectional study. Urol. J. 2016, 13, 2552-2561. [CrossRef] [PubMed]

15. Felde, G.; Ebbesen, M.H.; Hunskaar, S. Anxiety and depression associated with urinary incontinence. A 10-year follow-up study from the Norwegian HUNT study (EPINCONT). Neurourol. Urodyn. 2017, 36, 322-328. [CrossRef]

16. Crowley, K. Sleep and sleep disorders in older adults. Neuropsychol. Rev. 2011, 21, 41-53. [CrossRef]

17. Wyskida, M.; Wieczorowska-Tobis, K.; Chudek, J. Prevalence and factors promoting the occurrence of vitamin D deficiency in the elderly. Postepy Hig. Med. Dosw. 2017, 71, 198-204. [CrossRef] 
18. Ferrucci, L.; Guralnik, J.M.; Studenski, S.; Fried, L.P.; Cutler, G.B.; Walston, J.D. Designing randomized, controlled trials aimed at preventing or delaying functional decline and disability in frail, older persons: A consensus report. J. Am. Geriatr. Soc. 2004, 52, 625-634. [CrossRef]

19. Fried, L.P.; Tangen, C.M.; Walston, J.; Newman, A.B.; Hirsch, C.; Gottdiener, J.; Seeman, T.; Tracy, R.; Kop, W.J.; Burke, G.; et al. Frailty in older adults: Evidence for a phenotype. J. Gerontol. Ser. Biol. Sci. Med. Sci. 2001, 56, M146-M157. [CrossRef]

20. Rodriguez-Mañas, L.; Fried, L.P. Frailty in the clinical scenario. Lancet 2015, 385, e7-e9. [CrossRef]

21. Freiberger, E.; De vreede, P.; Schoene, D.; Rydwik, E.; Mueller, V.; Frändin, K.; Hopman-Rock, M. Performance-based physical function in older community-dwelling persons: A systematic review of instruments. Age Ageing 2012, 41, 712-721. [CrossRef] [PubMed]

22. Scully, T. Demography: To the limit. Nature 2012, 492, S2-S3. [CrossRef] [PubMed]

23. World Health Organization United Nations Department of Economics and Social Affairs: Population Division. World Population Ageing: 1950-2050. Available online: http://www.un.org/\%0Aesa/population/publications/ worldageing19502050/. (accessed on 31 March 2020).

24. Castell, M.V.; Gutiérrez-Misis, A.; Sánchez-Martínez, M.; Prieto, M.A.; Moreno, B.; Nuñez, S.; Triano, R.; De Antonio, M.P.; Mateo, C.; Cano, M.D.; et al. Effectiveness of an intervention in multicomponent exercise in primary care to improve frailty parameters in patients over 70 years of age (MEFAP-project), a randomised clinical trial: Rationale and study design. BMC Geriatr. 2019, 19, 1-9. [CrossRef] [PubMed]

25. Gates, S.; Fisher, J.D.; Cooke, M.W.; Carter, Y.H.; Lamb, S.E. Multifactorial assessment and targeted intervention for preventing falls and injuries among older people in community and emergency care settings: Systematic review and meta-analysis. BMJ 2008, 336, 130-133. [CrossRef] [PubMed]

26. Izquierdo, M.; Casas-Herrero, A.; Martínez-Velilla, N.; Alonso-Bouzón, C.; Rodríguez-Mañas, L. An example of cooperation for implementing programs associated with the promotion of exercise in the frail elderly. European Erasmus + «Vivifrail» program. Rev. Esp. Geriatr. Gerontol. 2017, 52, 110-111. [CrossRef] [PubMed]

27. Lutz, W.; Sanderson, W.; Scherbov, S. Doubling of world population unlikely. Nature 1997, 387, $803-805$. [CrossRef]

28. Bouaziz, W.; Lang, P.O.; Schmitt, E.; Kaltenbach, G.; Geny, B.; Vogel, T. Health benefits of multicomponent training programmes in seniors: A systematic review. Int. J. Clin. Pract. 2016, 70, 520-536. [CrossRef]

29. Hildebrand, M.; Van Hees, V.T.; Hansen, B.H.; Ekelund, U. Age group comparability of raw accelerometer output from wrist-and hip-worn monitors. Med. Sci. Sports Exerc. 2014, 46, 1816-1824. [CrossRef]

30. Physical Activity Guidelines Advisory Committee. Physical activity guidelines advisory committee report, 2008: To the Secretary of Health and Human Services. Nutr. Rev. 2009, 67, 114-120.

31. Fiuza-Luces, C.; Garatachea, N.; Berger, N.A.; Lucia, A. Exercise is the real polypill. Physiology 2013, 28, 330-358. [CrossRef]

32. Fragala, M.S.; Cadore, E.L.; Dorgo, S.; Izquierdo, M.; Kraemer, W.J.; Peterson, M.D.; Ryan, E.D. Resistance training for older adults: Position statement from the national strength and conditioning association. J. Strength Cond. Res. 2019, 33, 2019-2052. [CrossRef] [PubMed]

33. Colley, R.C.; Garriguet, D.; Janssen, I.; Craig, C.L.; Clarke, J.; Tremblay, M.S. Physical activity of canadian children and youth: Accelerometer results from the 2007 to 2009 canadian health measures survey. Health Rep. 2011, 22.

34. Sardinha, L.B.; Santos, D.A.; Silva, A.M.; Baptista, F.; Owen, N. Breaking-up sedentary time is associated with physical function in older adults. J. Gerontol. 2015, 70, 119-124. [CrossRef] [PubMed]

35. Cadore, E.L.; Casas-Herrero, A.; Zambom-Ferraresi, F.; Idoate, F.; Millor, N.; Gómez, M.; Rodriguez-Mañas, L.; Izquierdo, M. Multicomponent exercises including muscle power training enhance muscle mass, power output, and functional outcomes in institutionalized frail nonagenarians. Age 2014, 36, 773-785. [CrossRef] [PubMed]

36. Cadore, E.L.; Rodríguez-Mañas, L.; Sinclair, A.; Izquierdo, M. Effects of different exercise interventions on risk of falls, gait ability, and balance in physically frail older adults: A systematic review. Rejuvenation Res. 2013, 16, 105-114. [CrossRef]

37. Esain, I.; Rodriguez-Larrad, A.; Bidaurrazaga-Letona, I.; Gil, S.M. Health-related quality of life, handgrip strength and falls during detraining in elderly habitual exercisers. Health Qual. Life Outcomes 2017, 15. [CrossRef] 
38. Rockwood, K.; Song, X.; MacKnight, C.; Bergman, H.; Hogan, D.B.; McDowell, I.; Mitnitski, A. A global clinical measure of fitness and frailty in elderly people. Can. Med. Assoc. J. 2005, 173, 489-495. [CrossRef]

39. Slade, S.C.; Dionne, C.E.; Underwood, M.; Buchbinder, R. Consensus on Exercise Reporting Template (CERT): Explanation and elaboration statement. Br. J. Sports Med. 2016, 50, 1428-1437. [CrossRef]

40. De Labra, C.; Guimaraes-Pinheiro, C.; Maseda, A.; Lorenzo, T.; Millán-Calenti, J.C. Effects of physical exercise interventions in frail older adults: A systematic review of randomized controlled trials Physical functioning, physical health and activity. BMC Geriatr. 2015, 15. [CrossRef]

41. Abellan Van Kan, G.; Vellas, B. Is the mini nutritional assessment an appropriate tool to assess frailty in older adults? J. Nutr. Heal. Aging 2011, 15, 159-161. [CrossRef]

42. Visvanathan, R. Under-nutrition in older people: A serious and growing global problem! J. Postgrad. Med. 2003, 49, 352-360. [PubMed]

43. Cederholm, T.; Barazzoni, R.; Austin, P.; Ballmer, P.; Nutrition, G.B.-C. Undefined ESPEN Guidelines on Definitions and Terminology of Clinical Nutrition; Elsevier: Amsterdam, The Netherlands, 2017.

44. De La Fuente-Arrillaga, C.; Vzquez Ruiz, Z.; Bes-Rastrollo, M.; Sampson, L.; Martinez-González, M.A. Reproducibility of an FFQ validated in Spain. Public Health Nutr. 2010, 13, 1364-1372. [CrossRef] [PubMed]

45. Martin-moreno, J.M.; Boyle, P.; Gorgojo, L.; Maisonneuve, P.; Fernandez-rodriguez, J.C.; Salvini, S.; Willett, W.C. Development and validation of a food frequency questionnaire in Spain. Int. J. Epidemiol. 1993, 22, 512-519. [CrossRef] [PubMed]

46. Abizanda, P.; López, M.D.; García, V.P.; de Dios Estrella, J.; da Silva González, Á.; Vilardell, N.B.; Torres, K.A. Effects of an oral nutritional supplementation plus physical exercise intervention on the physical function, nutritional status, and quality of life in frail institutionalized older adults: The ACTIVNES study. J. Am. Med. Dir. Assoc. 2015, 16, 439.e9-439.e16. [CrossRef] [PubMed]

47. Sanchis, J.; Núñez, E.; Ruiz, V.; Bonanad, C.; Fernández, J.; Cauli, O.; García-Blas, S.; Mainar, L.; Valero, E.; Rodríguez-Borja, E.; et al. Usefulness of clinical data and biomarkers for the identification of frailty after acute coronary syndromes. Can. J. Cardiol. 2015, 31, 1462-1468. [CrossRef]

48. Halfon, M.; Phan, O.; Theta, D. Vitamin D: A review on its effects on muscle strength, the risk of fall, and frailty. Biomed. Res. Int. 2015, 2015, 1-11. [CrossRef]

49. Granic, A.; Hil, T.R.; Davies, K.; Jagger, C.; Adamson, A.; Siervo, M.; Kirkwood, T.B.L.; Mathers, J.C.; Sayer, A.A. Vitamin d status, muscle strength and physical performance decline in very old adults: A prospective study. Nutrients 2017, 9, 379. [CrossRef]

50. Zamboni, M.; Zoico, E.; Tosoni, P.; Zivelonghi, A.; Bortolani, A.; Maggi, S.; Di Francesco, V.; Bosello, O. Relation between vitamin D, physical performance, and disability in elderly persons. J. Gerontol. 2002, 57, M7-M11. [CrossRef]

51. Hirani, V.; Cumming, R.G.; Naganathan, V.; Blyth, F.; Le Couteur, D.G.; Handelsman, D.J.; Waite, L.M.; Seibel, M.J. Associations between serum 25-hydroxyvitamin D concentrations and multiple health conditions, physical performance measures, disability, and all-cause mortality: The concord health and ageing in men project. J. Am. Geriatr. Soc. 2014, 62, 417-425. [CrossRef]

52. Esain, I.; Gil, S.M.; Bidaurrazaga-Letona, I.; Rodriguez-Larrad, A. Effects of 3 months of detraining on functional fitness and quality of life in older adults who regularly exercise. Aging Clin. Exp. Res. 2019, 31, 503-510. [CrossRef]

53. Henwood, T.R.; Taaffe, D.R. Detraining and retraining in older adults following long-term muscle power or muscle strength specific training. J. Gerontol. 2008, 63, 751-758. [CrossRef] [PubMed]

54. Lobo, A.; Carvalho, J.; Santos, P. Effects of training and detraining on physical fitness, physical activity patterns, cardiovascular variables, and HRQoL after 3 health-promotion interventions in institutionalized elders. Int. J. Family Med. 2010, 2010, 1-10. [CrossRef] [PubMed]

55. Toraman, N.F.; Ayceman, N. Effects of six weeks of detraining on retention of functional fitness of old people after nine weeks of multicomponent training. Br. J. Sports Med. 2005, 39, 565-568. [CrossRef] [PubMed]

56. Zwarenstein, M.; Treweek, S.; Gagnier, J.J.; Altman, D.G.; Tunis, S.; Haynes, B. Pragmatic trials in healthcare (Practihc) group. Improving the reporting of pragmatic trials: An extension of the CONSORT statement. BMJ 2008, 337, a2390. [CrossRef] [PubMed]

57. World Medical Association. World Medical Association Declaration of Helsinki: Ethical principles for medical research involving human subjects. JAMA 2013, 310, 2191-2194. [CrossRef] 
58. Kelley, G.A.; Kelley, K.S. Dropouts and compliance in exercise interventions targeting bone mineral density in adults: A meta-analysis of randomized controlled trials. J. Osteoporos. 2013, 2013. [CrossRef]

59. Morley, J.E.; Malmstrom, T.K.; Miller, D.K. A simple frailty questionnaire (FRAIL) predicts outcomes in middle aged african americans. J. Nutr. Health Aging 2012, 16, 601-608. [CrossRef]

60. Guralnik, J.M.; Simonsick, E.M.; Ferrucci, L.; Glynn, R.J.; Berkman, L.F.; Blazer, D.G.; Scherr, P.A.; Wallace, R.B. A short physical performance battery assessing lower extremity function: Association with self-reported disability and prediction of mortality and nursing home admission. J. Gerontol. 1994, 49, M85-M94. [CrossRef]

61. Treacy, D.; Hassett, L. The short physical performance battery. J. Physiother. 2018, 64, 61. [CrossRef]

62. Rodriguez-Larrad, A.; Arrieta, H.; Rezola, C.; Kortajarena, M.; Yanguas, J.J.; Iturburu, M.; Susana, M.G.; Irazusta, J. Effectiveness of a multicomponent exercise program in the attenuation of frailty in long-term nursing home residents: Study protocol for a randomized clinical controlled trial. BMC Geriatr. 2017, 17, 60. [CrossRef]

63. Casas-Herrero, A.; Anton-Rodrigo, I.; Zambom-Ferraresi, F.; Sáez De Asteasu, M.L.; Martinez-Velilla, N.; Elexpuru-Estomba, J.; Marin-Epelde, I.; Ramon-Espinoza, F.; Petidier-Torregrosa, R.; Sanchez-Sanchez, J.L.; et al. Effect of a multicomponent exercise programme (VIVIFRAIL) on functional capacity in frail community elders with cognitive decline: Study protocol for a randomized multicentre control trial. Trials 2019, 20, 1-12. [CrossRef] [PubMed]

64. Rikli, R.; Jones, C. Senior Fitness Test Manual, 2nd ed.; Tocco, A., Maurer, K., Cox, K., Shea, B., Feeney, J., Huls, S., Eds.; Human Kinetics: Champaign, IL, USA, 2002; ISBN 978-1-4504-1118-9.

65. Oja, P.; Tuxworth, B. Eurofit Para Adultos: Evaluación de la Aptitud Física en Relación con la Salud; Ministry of Education and Culture: Montevideo, Uruguay, 1998.

66. Podsiadlo, D.; Richardson, S. The timed "up \& go": A test of basic functional mobility for frail elderly persons. J. Am. Geriatr. Soc. 1991, 39, 142-148. [PubMed]

67. Hofheinz, M.; Mibs, M. The prognostic validity of the timed up and go test with a dual task for predicting the risk of falls in the elderly. Gerontol. Geriatr. Med. 2016, 2, 233372141663779. [CrossRef] [PubMed]

68. Carvalho, C.; Sunnerhagen, K.S.; Willén, C. Walking speed and distance in different environments of subjects in the later stage post-stroke. Physiother. Theory Pract. 2010, 26, 519-527. [CrossRef]

69. Kim, H.; Park, I.; On, L. Reliability and validity of gait speed test. J Exerc. Nutr. Biochem. 2016, 20, 46-50. [CrossRef]

70. Izquierdo, M. Multicomponent physical exercise program: Vivifrail. Nutr. Hosp. 2019, 36, 50-56. [CrossRef]

71. Marfell-Jones, M.J.; Stewart, A.D.; De Ridder, J.H. International Standards for Anthropometric Assessment; International Society for the Advancement of Kinanthropometry: Wellington, New Zealand, 2012; ISBN 0620362073.

72. Plasqui, G.; Bonomi, A.G.; Westerterp, K.R. Daily physical activity assessment with accelerometers: New insights and validation studies. Obes. Rev. 2013, 14, 451-462. [CrossRef]

73. Washburn, R.A.; Smith, K.W.; Jette, A.M.; Janney, C.A. The physical activity scale for the elderly (PASE): Development and evaluation. J. Clin. Epidemiol. 1993, 46, 153-162. [CrossRef]

74. López-Rodríguez, C.; Laguna, M.; Gómez-Cabello, A.; Gusi, N.; Espino, L.; Villa, G.; Pedrero-Chamizo, R.; Casajus, J.A.; Ara, I.; Aznar, S. Validation of the self-report EXERNET questionnaire for measuring physical activity and sedentary behavior in elderly. Arch. Gerontol. Geriatr. 2017, 69, 156-161. [CrossRef]

75. Chasan-taber, L.; Erickson, J.B.; Nasca, P.C.; Chasan-taber, S.; Freedson, P.S. Validity and reproducibility of a physical activity questionnaire in women. Med. Sci. Sports Exerc. 2002, 34, 987-992. [CrossRef]

76. Chasan-Taber, L.; Erickson, J.B.; McBride, J.W.; Nasca, P.C.; Chasan-Taber, S.; Freedson, P.S. Reproducibility of a self-administered lifetime physical activity questionnaire among female college alumnae. Am. J. Epidemiol. 2002, 155, 282-289. [CrossRef] [PubMed]

77. Guirao-Goris, J.A.; Cabrero-García, J.; Moreno Pina, J.P.; Muñoz-Mendoza, C.L. Revisión estructurada de los cuestionarios y escalas que miden la actividad física en los adultos mayores y ancianos. Gac. Sanit. 2009, 23, 334-e51. [CrossRef] [PubMed]

78. Sattler, M.C.; Jaunig, J.; Watson, E.D.; van Poppel, M.N.M.; Mokkink, L.B.; Terwee, C.B.; Dietz, P. Physical activity questionnaires for pregnancy: A systematic review of measurement properties. Sport. Med. 2018, 48, 2317-2346. [CrossRef] [PubMed] 
79. Martínez-González, M.Á.; Corella, D.; Salas-salvadó, J.; Ros, E.; Covas, M.I.; Fiol, M.; Wärnberg, J.; Arós, F.; Ruíz-Gutiérrez, V.; Lamuela-Raventós, R.M.; et al. Cohort profile: Design and methods of the PREDIMED study. Int. J. Epidemiol. 2012, 41, 377-385. [CrossRef] [PubMed]

80. Papadaki, A.; Johnson, L.; Toumpakari, Z.; England, C.; Rai, M.; Toms, S.; Penfold, C.; Zazpe, I.; Martínez-González, M.A.; Feder, G. Validation of the English version of the 14-item mediterranean diet adherence screener of the PREDIMED study, in people at high cardiovascular risk in the UK. Nutrients 2018, 10, 138. [CrossRef]

81. Schröder, H.; Fitó, M.; Estruch, R.; Martínez-González, M.A.; Corella, D.; Salas-Salvadó, J.; Lamuela-Raventós, R.; Ros, E.; Salaverría, I.; Fiol, M.; et al. A short screener is valid for assessing mediterranean diet adherence among older spanish men and women. J. Nutr. 2011, 141, 1140-1145. [CrossRef]

82. Mataix, J. Tabla de Composición de Alimentos, 5th ed.; Universidad de Granada, Ed.; Faculty of Pharmacy: Granada, Spain, 2009.

83. Moreiras, O.; Carbajal, Á.; Cabrera, L.; Cuadrado, C. Tablas de Composición de Alimentos; Organizacion Panamericana de la Salud: Washington, DC, USA, 2003.

84. Folstein, M.F.; Folstein, S.E.; McHugh, P.R. "Mini-mental state". A practical method for grading the cognitive state of patients for the clinician. J. Psychiatr. Res. 1975, 12, 189-198. [CrossRef]

85. Group, T.E. EuroQol-A new facility for the measurement of health-related quality of life. Health Policy 1990, 16, 199-208. [CrossRef]

86. Lawton, M.P.; Brody, E.M. Assessment of older people: Self-maintaining and instrumental activities of daily living. Gerontologist 1965, 9, 179-186. [CrossRef]

87. Cabañero-Martínez, M.J.; Cabrero-García, J.; Richart-Martínez, M.; Muñoz-Mendoza, C.L. The Spanish versions of the Barthel index (BI) and the Katz index (KI) of activities of daily living (ADL): A structured review. Arch. Gerontol. Geriatr. 2009, 49, e77-e84. [CrossRef]

88. Mahoney, F.I.; Barthel, D.W. Functional evaluation: The Barthel Index: A simple index of independence useful in scoring improvement in the rehabilitation of the chronically ill. Md. State Med. J. 1965, 14, 61-65. [PubMed]

89. Sainsbury, A.; Seebass, G.; Bansal, A.; Young, J.B. Reliability of the Barthel Index when used with older people. Age Ageing 2005, 34, 228-232. [CrossRef] [PubMed]

90. Yardley, L.; Beyer, N.; Hauer, K.; Kempen, G.; Piot-Ziegler, C.; Todd, C. Development and initial validation of the Falls Efficacy Scale-International (FES-I). Age Ageing 2005, 34, 614-619. [CrossRef] [PubMed]

91. Leyton, M.; Batista, M.; Lobato, S.; JimÉnez, R. Validation of the questionnaire of the transtheoretical model of change of physical exercise Validación del cuestionario del modelo transteőrico del cambio de ejercicio físico. Rev. Int. Med. Ciencias Act. Fis. Deport. 2019, 19, 329-350. [CrossRef]

92. Marcus, B.H.; Simkin, L.R. The transtheoretical model: Applications to exercise behavior. Med. Sci. Sports Exerc. 1994, 26, 1400-1404. [CrossRef] [PubMed]

93. Marijuán, P.C.; Montero-Marín, J.; Navarro, J.; García-Campayo, J.; Del Moral, R. The "sociotype" construct: Gauging the structure and dynamics of human sociality. PLoS ONE 2017, 12, e0189568. [CrossRef]

94. Simundic, A.; Bölenius, K.; Cadamuro, J.; Church, S.; Cornes, M.P.; van Dongen-Lases, E.C.; Hoke, R. Joint EFLM-COLABIOCLI Recommendation for venous blood sampling. Clin. Chem. Lab. Med. 2018, 56, 2015-2038. [CrossRef]

95. Binder, E.F.; Schechtman, K.B.; Ehsani, A.A.; Steger-May, K.; Brown, M.; Sinacore, D.R.; Yarasheski, K.E.; Holloszy, J.O. Effects of exercise training on frailty in community-dwelling older adults: Results of a randomized, controlled trial. J. Am. Geriatr. Soc. 2002, 50, 1921-1928. [CrossRef]

96. Means, K.M.; Rodell, D.E.; O'Sullivan, P.S. Balance, mobility, and falls among community-dwelling elderly persons: Effects of a rehabilitation exercise program. Am. J. Phys. Med. Rehabil. 2005, 84, 238-250. [CrossRef]

97. Vaughan, S.; Wallis, M.; Polit, D.; Steele, M.; Shum, D.; Morris, N. The effects of multimodal exercise on cognitive and physical functioning and brain-derived neurotrophic factor in older women: A randomised controlled trial. Age Ageing 2014, 43, 623-629. [CrossRef]

98. Nakamura, Y.; Tanaka, K.; Yabushita, N.; Sakai, T.; Shigematsu, R. Effects of exercise frequency on functional fitness in older adult women. Arch. Gerontol. Geriatr. 2007, 44, 163-173. [CrossRef] [PubMed]

99. Coubard, O.A.; Duretz, S.; Lefebvre, V.; Lapalus, P.; Ferrufino, L. Practice of contemporary dance improves cognitive flexibility in aging. Front. Aging Neurosci. 2011, 3, 1-12. [CrossRef] [PubMed] 
100. Ward, D.S.; Evenson, K.R.; Vaughn, A.; Rodgers, A.B.; Troiano, R.P. Accelerometer use in physical activity: Best practices and research recommendations. Med. Sci. Sports Exerc. 2005, 37 (Suppl. 11), S582-S588. [CrossRef] [PubMed]

101. Cadore, E.L.; Izquierdo, M. Muscle power training: A hallmark for muscle function retaining in frail clinical setting. J. Am. Med. Dir. Assoc. 2018, 19, 190-192. [CrossRef] [PubMed]

102. Cadore, E.L.; Pinto, R.S.; Reischak-Oliveira, Á.; Izquierdo, M. Explosive type of contractions should not be avoided during resistance training in elderly. Exp. Gerontol. 2018, 102, 81-83. [CrossRef]

103. Reid, K.F.; Fielding, R.A. Skeletal muscle power: A critical determinant of physical functioning in older adults. Exerc. Sport Sci. Rev. 2012, 40, 4-12. [CrossRef]

104. Tarazona-Santabalbina, F.J.; Gómez-Cabrera, M.C.; Pérez-Ros, P.; Martínez-Arnau, F.M.; Cabo, H.; Tsaparas, K.; Salvador-Pascual, A.; Rodriguez-Mañas, L.; Viña, J. A multicomponent exercise intervention that reverses frailty and improves cognition, emotion, and social networking in the community-dwelling frail elderly: A randomized clinical trial. J. Am. Med. Dir. Assoc. 2016, 17, 426-433. [CrossRef]

105. Bréchat, P.-H.; Lonsdorfer, J.; Vogel, T. Health promotion by safe, individualized, and accessible physical activities and sports. Presse Med. 2007, 36, 379-380. [CrossRef]

106. Farooqui, M.A.; Tan, Y.T.; Bilger, M.; Finkelstein, E.A. Effects of financial incentives on motivating physical activity among older adults: Results from a discrete choice experiment. BMC Public Health 2014, 14, 141. [CrossRef]

(C) 2020 by the authors. Licensee MDPI, Basel, Switzerland. This article is an open access article distributed under the terms and conditions of the Creative Commons Attribution (CC BY) license (http://creativecommons.org/licenses/by/4.0/). 